\title{
The Role of NMDA and Non-NMDA Excitatory Amino Acid Receptors in the Excitation of Primate Spinothalamic Tract Neurons by Mechanical, Chemical, Thermal, and Electrical Stimuli
}

\author{
P. M. Dougherty, J. Palecek, ${ }^{\mathrm{a}}$ V. Paleckova, ${ }^{\mathrm{a}}$ L. S. Sorkin, ${ }^{\mathrm{b}}$ and W. D. Willis \\ Department of Anatomy and Neurosciences and The Marine Biomedical Institute, University of Texas Medical Branch, \\ Galveston, Texas 77555-0843
}

\begin{abstract}
The role of excitatory amino acids (EAAs) in the excitation of monkey spinothalamic tract (STT) neurons following activation of cutaneous primary afferent fibers by noxious and non-noxious stimuli was investigated. The responses of STT neurons to either NMDA or non-NMDA EAA ligands were blocked by infusion of specific antagonists through a microdialysis fiber into the region surrounding the cells. Our results show that blockade of non-NMDA receptors results in a nearly complete elimination of the responses of STT neurons to all stimuli. Blockade of NMDA receptors results in an attenuation of the responses to noxious stimuli but, in addition, prevents the development of the sensitization of STT neurons that is often observed after intradermal injection of capsaicin. These observations further support a role of EAAs in the transmission of sensory information from primary afferent fibers to dorsal horn neurons and a role for NMDA receptors in the generation of hyperalgesia.
\end{abstract}

Several lines of investigation have indicated that the excitatory amino acids (EAAs) glutamate (GLUT) and aspartate (ASP) participate in the chemical transmission of information from primary afferent fibers to dorsal horn neurons (see reviews by Puil, 1981; Watkins and Evans, 1981; Salt and Hill, 1983a; Mayer and Westbrook, 1987; Rustioni and Weinberg, 1989; Wilcox, 1991). However, no clear association of GLUT or ASP with a particular fiber type or response modality has been shown. For example, GLUT and ASP are found in both large and small dorsal root ganglion cells and large- and small-diameter primary afferent fibers (Wanaka et al., 1987; Battaglia and Rustioni, 1988; Westlund et al., 1989, 1990b), as well as in interneurons of the dorsal horn (Rizzoli, 1968; Fagg and Fostcr, 1983; Cotman et al., 1987; Storm-Mathisen and Ottersen, 1987). In addition, the release of both EAAs has been demonstrated following low- as well as high-intensity electrical stimulation of

\footnotetext{
Received Nov. 6, 1991; revised Feb. 7, 1992; accepted Mar. 12, 1992.

We thank Kelli Gondesen and Greg Robak for technical assistance and Griselda Gonzalez for assistance with the illustrations. This effort was supported by NIH Grants NS09743, NS07185, and NS11255, National Service Award NS08860, and an unrestricted grant from the Bristol-Myers Squibb Corporation.

Correspondence should be addressed to W. D. Willis, Department of Anatomy and Neurosciences and The Marine Biomedical Institute, University of Texas Medical Branch, 200 I Iniversity Boulevard, Galveston, TX 77555-0843.

a Permanent address: Institute of Physiology, Chechoslovak Academy of Science, Prague, 14220 Czechoslovakia.

b Present address: Department of Anesthesiology, University of California at San Diego, San Diego, CA 92037

Copyright (C) 1992 Society for Neuroscience $0270-6474 / 92 / 123025-17 \$ 05.00 / 0$
}

peripheral nerves and after mechanical or chemical stimulation of the skin (Skilling et al., 1988; Liu et al., 1989; Kangrga and Randic, 1991; Sorkin et al., 1992).

The postsynaptic sites of action of the EAAs on neurons in rat, cat, and monkey include both NMDA and non-NMDA receptors (McLennan and Lodge, 1979; Watkins and Evans, 1981; Peet et al., 1983; Salt and Hill, 1983b; Childs et al., 1988). Several groups have suggested that the non-NMDA receptors mediate the responses of dorsal horn neurons to monosynaptic inputs while the NMDA receptors mediate the responses to polysynaptic inputs (Davies and Watkins, 1983; Peet et al., 1983; Schneider and Perl, 1985; Schouenborg and Sjolund, 1986; King et al., 1988; Morris, 1989). Later studies associated the non-NMDA receptors with low-threshold inputs, presumably those transmitted by large myelinated fibers, while the NMDA receptors have been proposed to mediate nociceptive inputs, presumably from $\mathrm{A} \delta$ and $\mathrm{C}$ fibers (Gerber and Randic, 1989a,b; Dickenson and Sullivan, 1990). Behavioral studies have shown that administration of agonists specific to either of the EAA receptor subtypes produces aversive behaviors, but activation or blockade of NMDA receptors is particularly associated with the production or blockade of responses interpreted as reflecting hyperalgesia (Cahusac et al., 1984; Aanonsen and Wilcox, 1987; Raigorodsky and Urca, 1987; Yaksh, 1989).

Previous work by our group on monkey spinothalamic tract (STT) neurons did not support the idea that NMDA receptors are specifically associated with nociceptive transmission. For example, we have shown that iontophoretic administration of an NMDA antagonist, DL-2-amino-7-phosphonoheptanoic acid (AP7), can reduce responses of individual STT cells to innocuous brushing of the skin as well as to noxious pinching of the skin (Dougherty and Willis, 199 la). Furthermore, iontophoretic release of NMDA results in a significant increase of the average response of STT cells to brushing but not to pinching of the skin, although individual cells showed increased responses to pinching. The non-NMDA agonist quisqualic acid also affects the responses of many individual STT cells to both innocuous and noxious mechanical stimuli. Similar results have been reported following the iontophoretic release of NMDA and AMPA on the responses of rat projection neurons to mechanical stimulation of skin (Aanonsen et al., 1990). In addition, iontophoretic application of GLUT also results in an expansion of the lowthreshold as well as the high-threshold receptive fields of dorsal horn neurons in the cat (Zieglgansberger and Herz, 1971). However, in each of these studies, either technical factors or limited sample sizes prevented the development of a clear picture of 
the role of different kinds of EAA receptors in the responses of STT cells to activation by different kinds of afferent stimuli.

The goal of the present study was to determine the effects of specific antagonists of NMDA or non-NMDA receptors on the responses of STT neurons to mechanical, chemical, and thermal stimulation of the skin, and to electrical activation of large dorsal root afferent fibers. To overcome the difficulty in applying adequate concentrations of EAA antagonists by iontophoresis, we have used a microdialysis system to deliver these agents into the dorsal horn. We verified receptor blockade by the antagonism of the discharges evoked by EAA agonists released into the vicinity of STT neurons by iontophoresis.

\section{Materials and Methods}

Animal preparation. The experiments were performed on 12 young adult monkeys (Macaca fascicularis) weighing $2.0-3.4 \mathrm{~kg}$. The animals were initially tranquilized by ketamine $(10.0 \mathrm{mg} / \mathrm{kg}$, i.m.) during transportation to the laboratory. Anesthesia was established with a gaseous mixture of halothane, nitrous oxide, and oxygen followed by an intravenous dose of $\alpha$-chloralose $(60.0 \mathrm{mg} / \mathrm{kg}$ ). Anesthesia was later maintained by intravenous infusion of pentobarbital $(5.0 \mathrm{mg} / \mathrm{kg} / \mathrm{hr})$. The level of anesthesia was checked periodically by examining pupillary size and reflexes and monitored continuously by recording expired $\mathrm{CO}_{2}$ and heart rate. The monkeys were paralyzed with gallamine triethiodide $(20.0 \mathrm{mg} / \mathrm{hr})$ and artificially ventilated. End-tidal $\mathrm{CO}_{2}$ was kept between $3.5 \%$ and $4.5 \%$, and core temperature was maintained between $37^{\circ} \mathrm{C}$ and $38^{\circ} \mathrm{C}$ by a servo-controlled heating blanket. All procedures were reviewed by the local Animal Care and Use Committee and were consistent with the guidelines of the International Association for the Study of Pain and the NIH guide for the care and use of laboratory animals.

The lumbar enlargement was exposed by a laminectomy, and the spinal cord was covered by a pool of warmed mineral oil. A partial craniotomy allowed the introduction of a stainless steel monopolar electrode into the ventral posterior lateral nucleus of the right thalamus (VPL; A $8.0 \mathrm{~mm}, \mathrm{~L} 8.0 \mathrm{~mm}, 16.0-18.0 \mathrm{~mm}$ from the surface of the brain); the location of the electrode tip was verified by recording responses evoked by electrical stimulation of the left dorsal funiculus and by mechanical stimulation of the left distal hindlimb.

Experimental protocol. A seven-barrel micropipette was used to apply EAA agonists by microiontophoresis and to record single-unit discharges in the lumbar enlargement (Willcockson et al., 1984a,b; Dougherty and Willis, 1991a,b; Dougherty et al., 1992). Recordings from STT cells were made within $750 \mu \mathrm{m}$ from the nearest edge of the microdialysis fiber and were generally much closer than this. Variation in the distance of the recording sites from the fiber did not result in any apparent differences in the results obtained other than in latency of onset of the antagonist effects and the duration of the subsequent washout of the antagonists. In some animals more than one cell was studied. In these cases, either more than one fiber was used or the dialysis fiber (and VPL electrode) was positioned on the contralateral side. Extracellular activity was monitored with a low-impedance (3-6 M $\Omega$ ) carbon filament in the center barrel of the electrode array, and drugs were delivered from the surrounding outer barrels. Unit activity was observed on analog and digital storage oscilloscopes and fed to a window discriminator interfaced with a computer for data storage and later analysis. Spike size and configuration were continuously monitored on the digital oscilloscope to confirm that activity of the same cell was recorded throughout the experiment. This was found useful to ensure that the relationship of the recording electrode to the target cell was maintained, as well as to exclude the discharges of neighboring cells. STT neurons were identified using antidromic search stimuli $(0.75 \mathrm{~mA}, 200 \mu \mathrm{sec}$, at $3.0 \mathrm{~Hz})$ applied in the VPL nucleus. The antidromic spikes occurred at fixed latency, showed collision with orthodromic spikes at appropriate intervals, and followed high-frequency $(333-500 \mathrm{~Hz})$ stimulus trains.

The microdialysis fiber used to administer the EAA antagonists was prepared and the active zone positioned in the dorsal horn as previously described (Sorkin et al., 1988). Briefly, the fibers were fashioned from $30 \mathrm{~cm}$ lengths of Cuprophan tubing (150 $\mu \mathrm{m}$ i.d., $9-\mu \mathrm{m}$-thick wall) with a $9 \mathrm{kDa}$ molecular weight cutoff (Spectrum) and coated with a thin layer of silicon rubber (Dow Chemical 3140 RTN coating) except for a $1 \mathrm{~mm}$ length intended to be the active dialysis zone. Any fiber that exceeded a final outside diameter of $250 \mu \mathrm{m}$ was discarded. The diameter of most fibers was between 210 and $230 \mu \mathrm{m}$. A stainless steel dissecting pin cemented in the lumen at one end of the fiber was passed through the exposed spinal cord just below the dorsal root entry zone. The attached dialysis fiber was pulled through the spinal cord until a mark $1 \mathrm{~mm}$ from the active zone was aligned with the edge of the cord. The pin was then cut off and the free end of the dialysis fiber attached with cyanoacrylate to PE-20 tubing connected to a $5 \mathrm{ml}$ syringe. The syringe was seated in an infusion pump and a constant flow of $5 \mu \mathrm{l} / \mathrm{min}$ of artificial cerebrospinal fluid (ACSF) was initiated. The formulation of the ACSF was the same as used in previous work by our group (Sorkin et al., 1992) and contained the following (in mm): $151.1 \mathrm{Na}^{+}, 2.6 \mathrm{~K}^{+}, 0.9$ $\mathrm{Mg}^{2+}, 1.3 \mathrm{Ca}^{2+}, 122.7 \mathrm{Cl}^{-}, 21.0 \mathrm{HCO}_{3}^{-}, 2.5 \mathrm{HPO}_{4}{ }^{2-}, 3.5$ dextrose, bubbled with $95 \%$ oxygen and $5 \% \mathrm{CO}_{2}$ (final pH 7.4) prior to each experiment. Later switching of the dialysis fiber from control ACSF to EAA-antagonist-containing ACSF [either DL-2-amino-7-phosphonoheptanoic acid (AP7) or 6-cyano-7-nitroquinoxaline-2,3-dione (CNQX)] was done with a CMA 110 liquid switch to prevent introduction of bubbles and loss of system pressure. The concentration of the antagonists in the ACSF was $2 \mathrm{~mm}$. Preliminary experiments in vitro have shown that at this perfusion rate for $1 \mathrm{hr}$, the concentration of AP7 in a small chamber containing approximately $100 \mu \mathrm{l}$ of ACSF surrounding the dialysis fiber was $13 \%$ of that being perfused. We presume that the delivery efficiency for CNQX was roughly equal to that for AP7. Hence, allowing for the barrier provided by the dialysis membrane, the concentration of the antagonists in the spinal cord would be in the range of 250-275 $\mu \mathrm{M}$. However, the tortuous diffusion path in the tissue (Benveniste et al., 1990) and extraction of these lipophilic molecules by membranes would reduce the actual concentrations at the recording sites by at least another order of magnitude to those typically used in bath applications in vitro, approximately $20 \mu \mathrm{M}$ for the non-NMDA antagonist CNQX and $50 \mu \mathrm{M}$ for the NMDA antagonists 2-amino-5phosphonovaleric acid and AP7 (Watkins and Olverman, 1987; Evans and Long, 1989; Gerber and Randic, 1989a,b; Chen and Huang, 1991).

The experiment on each cell began with the determination of control evoked activity to four sets of cutaneous stimuli: (1) mechanical, (2) chemical, (3) thermal, and (4) electrical. Prior to application of the mechanical stimuli, receptive fields were mapped with innocuous and noxious mechanical stimuli using a camel hair brush, finger taps, and brief applications of arterial clips to the skin. Five test points were then chosen and marked with ink for delivery of threc sets of mechanical stimuli. The five test points spanned a large receptive field, but sometimes extended beyond a medium-sized or small receptive field. The mechanical stimuli included brushing the skin with a camel hair brush in a stereotyped manner (BRUSH) and then sustained applications of two different-sized arterial clips to a fold of skin. The large clip (PRESS) produces a force of $144 \mathrm{gm} / \mathrm{mm}^{2}$ and induces a sense of firm pressure near threshold for pain when placed on human skin. The second clip (PINCH) exerts a force of $583 \mathrm{gm} / \mathrm{mm}^{2}$ and is distinctly painful. Prior to application of the mechanical stimuli, background activity was recorded for $2 \mathrm{~min}$. The stimulus set began with an additional recording of background activity for $10 \mathrm{sec}$, and then the BRUSH stimulus was applied to test point 1 for $10 \mathrm{sec}$; after a $10 \mathrm{sec}$ pause, the stimulus was applied to test point 2 for 10 sec. This sequence was followed until the stimulus had been applied to all five test sites. After the BRUSI stimuli had been delivered, the entire sequence was repeated twice more, first with the PRESS and then with the PINCH stimulus. Care was taken to ensure that the BRUSH responses on each occasion were maximal and that the PRESS and PINCH stimuli were applied to the same marked location and the responses recorded while allowing the clips to hang freely from the skin. Only a single set of mechanical stimuli was generally applied before injection of capsaicin (CAP); however, control experiments showed that repeated application of these nondamaging stimuli elicited consistent responses (Dougherty et al., 1992). Although the responses were not obtained by "blinded" investigators, they were obtained over prolonged periods from multiple locations and without observation of the oscilloscopes or the computerized record; hence, the investigators were "operationally blinded." Responses to mechanical stimuli were later used to categorize the cells as wide dynamic range (WDR) or high threshold (HT). WDR cells responded to all three mechanical stimuli, whereas HT cells responded weakly to BRUSH $(10 \%$ or less of the maximal response) or not at all. No low-threshold neurons were encountered in this study.

The thermal stimuli were applied using a feedback-controlled peltier thermode with an active area of $36 \mathrm{~mm}^{2}$ (Wilcox and Giesler, 1984). The adaptation temperature was set at $35^{\circ} \mathrm{C}$, and cycles of 5-sec-long 
heating pulses from $39^{\circ} \mathrm{C}$ to $53^{\circ} \mathrm{C}$ were applied in increments of $2^{\circ} \mathrm{C}$. A recovery period of $30 \mathrm{sec}$ was allowed between successive pairs of heat pulses.

The electrical stimuli were applied to a dorsal rootlet that innervated the distal hindlimb and entered the spinal cord adjacent to the recording site and microdialysis fiber. The rootlet was placed on a platinum bipolar electrode. Rectangular electrical shocks $(200 \mu \mathrm{sec})$ were applied to the root at strengths graded from threshold for induction of a local field potential (measured through the recording barrel of the multibarrel microelectrode) to 10 times threshold. Responses to these shocks were recorded as a local field potential, as evoked spikes of the STT neuron, and as a cord dorsum potential recorded with a $1 \mathrm{~mm}$ square platinum plate electrode placed upon the surface of the spinal cord between the dorsal rootlet and the microdialysis fiber. The field potentials were averaged on a Nicolet 4562 digital oscilloscope following a total of 25 shocks delivered at $3 \mathrm{sec}$ intervals for each stimulus strength. The times at which evoked spikes occurred were recorded in five poststimulus time histograms compiled from five stimulus repetitions at each strength.

EAAs were applied by five 10 -sec-long current pulses (or in some cases 5 sec pulses) that were incremented in steps of either 5 or $10 \mathrm{nA}$. The substances applied by microiontophoresis included the following EAA agonists: $N$-methyl-D-aspartic acid (NMDA; $0.05 \mathrm{M}, \mathrm{pH} 8.0$ ), L-glutamic acid (GLUT; $0.1 \mathrm{M}$, pH 8.0), L-aspartic acid (ASP; $0.1 \mathrm{M}$, pH 8.0), DL- $\alpha$-amino-3-hydroxy-5-methylisoxazoleproprionic acid (AMPA;0.25 M, pH 8.0), and L-kainic acid (KAIN; $0.1 \mathrm{M}, \mathrm{pH} 8.0$ ). The remaining barrel was filled with $2 \mathrm{M} \mathrm{NaCl}(\mathrm{pH} \mathrm{8.0)}$ for current balance. Retaining currents sufficient to prevent drug leakage (usually 10-15 nA) were used between drug applications. Net current at the electrode tip was continuously monitored and neutralized with the aid of a Medical Systems iontophoresis pump (model BH-2). The EAA agonists applied by iontophoresis and the EAA antagonists applied by microdialysis were obtained from Sigma Chemical Corporation or Research Biochemicals Incorporated.

Once the control responses to all stimulus sets were recorded, CAP was injected intradermally to activate $C$ fibers, using a method similar to that of Simone et al. $(1987,1989,1991)$ but with a higher concentration of CAP (Doughcrty and Willis, 1992). Bricfly, $0.1 \mathrm{ml}$ of a solution of 3\% CAP (in Tween 80 and saline) was injected intradermally into the center of the receptive field. The injection produced a skin bleb that was approximately $1 \mathrm{~cm}$ in diameter. In each case the injection was several centimeters from the nearest site chosen for application of the mechanical stimuli.

Following the recording of responses to the first CAP injection, a 1 hr recovery period was allowed and then the infusion was switched to deliver the ACSF containing an EAA antagonist. The antagonist was infused for 30-60 min, at which time the responses to NMDA (for AP7. ACSF) or AMPA (for CNQX-ACSF) were recorded to demonstrate blockade of EAA receptors near the STT cell under observation. The variation in infusion time was due to the small variations in the distances of the recording sites from the near edge of the dialysis fiber. Other than this variation in time for onset of the antagonist effects and subsequently the time necessary for washout of the antagonists, the variation of the distance of the recording sites from the fiber did not affect the overall efficacy of the antagonists in preventing EAA discharges or sensoryevoked responses. The responses to all remaining stimuli (EAAs, mechanical, thermal, and electrical) were then recorded in the presence of the receptor blockade. A second CAP dose was then injected at least 5 $\mathrm{cm}$ proximal of the first injection site and the responses obtained as described above. The infusion was then returned to ACSF alone and the receptor antagonist allowed to be at least partially washed out. Responses to all stimuli were monitored at 30-60 min intervals until signs of recovery from the antagonists were observed or the cell was lost. In two experiments CAP was not injected so that the effects of the NMDA antagonists on the responses to the mechanical and thermal stimuli could be evaluated without the complication of the transient sensitization produced by the chemical stimulus (Dougherty and Willis, 1992).

Data analysis. The stored digital record of unit activity was retrieved and analyzed off line. Accumulated frequency histograms were generated for all drug-evoked and sensory-evoked events. Background activity was subtracted from all events. Differences between responses at the same location, temperature, or individual iontophoretic doses were calculated by analysis of variance (Student Neuman-Keuls test). Responses of a single neuron were regarded as significantly changed when the responses to at least two of the five sites (mechanical stimuli) or ion- tophoretic pulses were significantly $(p<0.05)$ changed in the same direction (elevation or inhibition). Thermal responses were considered to show a significant change when a previously ineffective heat stimulus evoked a response (lowered threshold) or the responses increased for a given temperature. Grouped responses were determined by calculating the total number of spikes evoked by the individual stimulus sets delivered to each cell at each time point during the experiment. These total evoked responses were combined for various groups and differences from controls calculated using the Wilcoxon rank sum test. Averaged stimulus-response curves for thermal stimuli and for graded iontophoretic current pulses for each group were also calculated, and differences between these responses were determined using Wilcoxon's test. The responses of a cell to electrically evoked volleys in the dorsal root filament were compared using the paired $t$ test. The grouped responses were compared using Wilcoxon's test. Finally, for comparison of the relative effects of $C N Q X$ and AP7 on the various stimuli, the change in response of each cell to each stimulus was calculated as a percentage of the control response [(control response/antagonist response) $\times 100]$. These values were combined to yield a mean percentage change in response compared to control for all stimuli with each antagonist.

\section{Results}

General observations. Recordings were made from a total of 34 STT cells in 12 experiments. These included 25 cells classified as WDR neurons and 9 classified as HT neurons. The recording sites were located from 250 to $2290 \mu \mathrm{m}$ below the surface of the spinal cord, suggesting that the cell bodies were located in laminae I-VI of the dorsal horn (Owens, 1991). The mean depth (and SD) of recording for the WDR cells was $1526.25 \pm 393.2$ $\mu \mathrm{m}$ from the surface, and that for the HT cells was $1622.9 \pm$ $301.0 \mu \mathrm{m}$. The background activity of the cells ranged from 0.01 to 46.15 spikes/sec. The mean background activity of the WDR cells was $15.36 \pm 13.75$ spikes/sec, and that of the HT cells was $7.0 \pm 6.3 \mathrm{spikes} / \mathrm{sec}$. The mean antidromic latency of the WDR neurons was $6.26 \pm 3.0 \mathrm{msec}$, and that of the HT neurons was $6.8+2.7 \mathrm{msec}$.

A total of 19 cells was used for the experiments using AP7. These cells included 14 WDR neurons and 5 HT neurons. The mean depth of recording for this group was $1593.2 \pm 121.5 \mu \mathrm{m}$, the mean background activity was $11.9 \pm 9.6 \mathrm{spikes} / \mathrm{sec}$, and the mean antidromic latency was $5.43 \pm 0.51 \mathrm{msec}$. A total of 15 cells was used for the experiments using CNQX, and these included 11 WDR neurons and 4 HT neurons. The mean depth of recording of this second group was $1609 \pm 256.9 \mu \mathrm{m}$, the mean background activity was $15.78 \pm 15.5 \mathrm{spikes} / \mathrm{sec}$, and the mean antidromic latency was $7.71 \pm 3.43 \mathrm{msec}$.

For experiments using either type of EAA antagonist, there were no apparent differences in the effects of either the EAA agonists or antagonists on the responses of WDR versus HT cells. For example, the mean total responses of the different cell types to the EAA agonists differed by less than 1 spike/sec for NMDA and by 4.7 spikes/sec for AMPA. By definition, the responses of these cell types were different to the mechanical stimuli, and as previously reported (Dougherty and Willis, 1992), the responses to CAP were more pronounced for the WDR cells than for the HT cells. Despite differences in the sizes of the responses of the different cell types to the different sensory stimuli, the relative effects of the antagonists on the responses of the cells to the sensory stimuli were not different. For this reason, the results for the two types of cells were combined in the analysis. However, since our sample of STT cells was skewed in favor of WDR cells, we cannot exclude the possibility that differences in the responses of these cell types to particular EAA agonists or antagonists may exist. All cells used for the illustrations were WDR cells. 

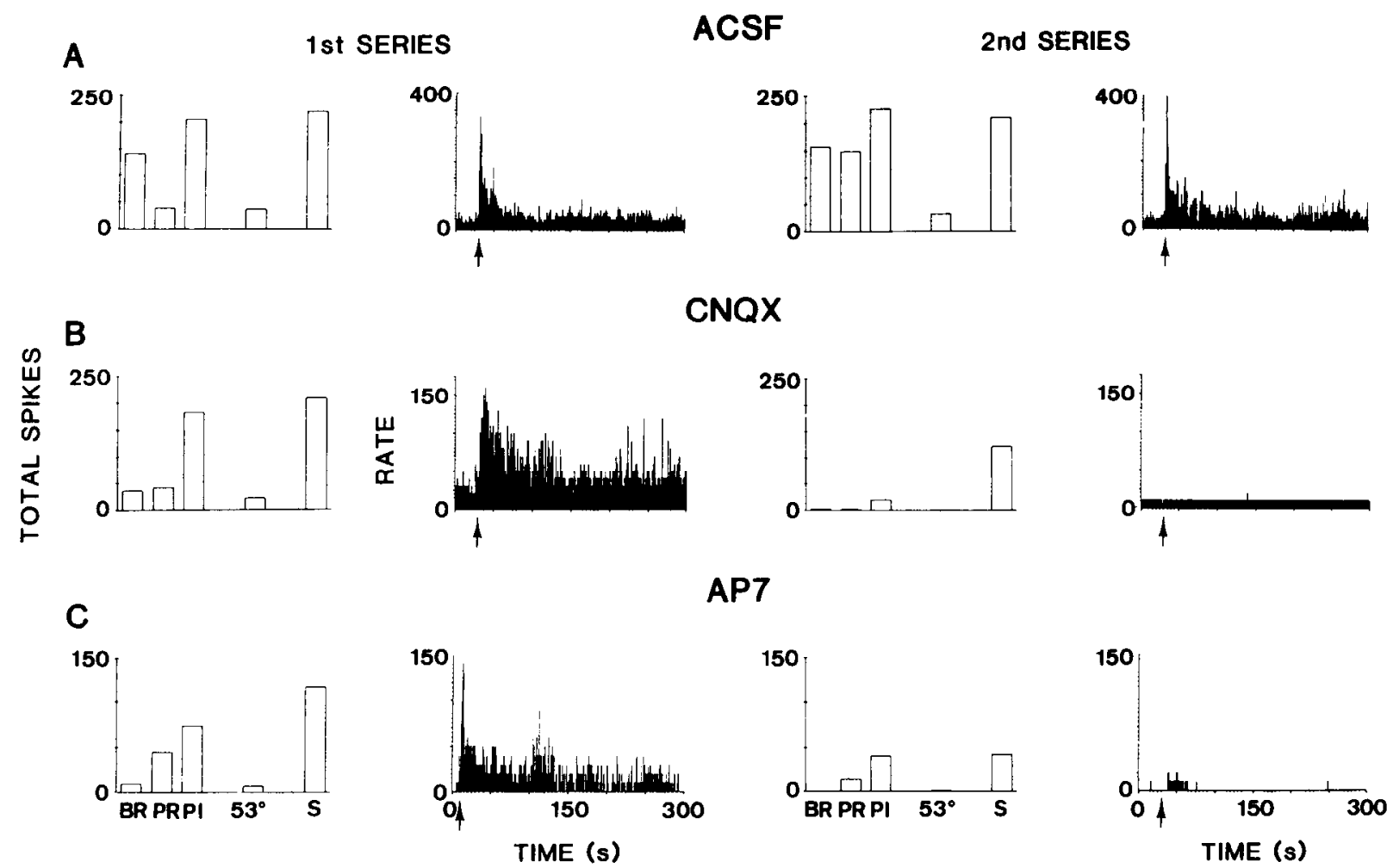

\section{AP7}

Figure 1. The bar graphs and rate histograms summarize the general protocol of most of the experiments. The bar graphs show the total number of spikes evoked above the background rate for the mechanical stimuli ( $B R$ for BRUSH, $P R$ for PRESS, $P I$ for PINCH), for a 5 sec thermal stimulus of $53^{\circ} \mathrm{C}$, and for electrical stimulation of a dorsal rootlet at 10 times threshold $(S)$. The histograms show the discharges of each neuron following the intradermal injection of CAP (at arrow). Bin widths in the rate histograms are $100 \mathrm{msec}$. The top row of bar graphs and histograms shows the control responses (first series) of an STT cell and the responses following a $2 \mathrm{hr}$ dialysis perfusion of the spinal cord with ACSF. The second row of the figure shows the responses of a representative STT cell before and during infusion of CNQX (in ACSF), and the bottom row shows the responses of a third representative STT cell before and then during infusion of AP7.

We did not study the responses of any neurons before and then following insertion of a microdialysis fiber through the spinal cord, and therefore we cannot rule out the possibility that this procedure may have altered the responses of the cells under study. However, all recordings were conducted no sooner than $2-3 \mathrm{hr}$ following fiber insertion, which is sufficient time for the stabilization of extracellular concentrations of several neurotransmitter levels (Sorkin et al., 1988, 1992). In addition, the background discharge rates of the cells remained stable throughout the control recordings and the mean rates for the cells in our study are comparable to those observed in previous studies in which no microdialysis fibers were passed through the spinal cord (Dougherty and Willis, 1991a,b, 1992; Dougherty et al., 1992). Moreover, the magnitudes of the control responses to the mechanical stimuli and to CAP were comparable to those observed in our previous studies.

General protocol for experiments. The experiments involved the assessment of a large series of responses of STT cells to iontophoretic application of EAAs, mechanical and thermal stimulation of the skin, intradermal injection of CAP, and electrically evoked volleys in a dorsal root filament before, during, and after infusion of an EAA antagonist into the dorsal horn by microdialysis. For the analysis of changes in the responses produced by the EAA antagonists, we regarded the initial series of responses as the controls and the increases that often followed intradermal CAP as due to a transient sensitized state (Dougherty and Willis, 1992). For most STT cells, CAP produces increases in the responses to many of the stimuli lasting $1.5-2 \mathrm{hr}$ (cf. Dougherty and Willis, 1992). In the present experiments, a $1 \mathrm{hr}$ recovery period was allowed following the first intradermal injection of CAP, and then the EAA antagonist had to be infused by microdialysis for about $30-60 \mathrm{~min}$ before there was a sufficient blockade of the appropriate receptors in the vicinity of the STT cell under observation. Thus, at least 90-120 min had passed before the tests were begun to determine the effects of the EAA antagonists, and so we assumed that the responses observed after this time reflected the effects of the antagonists and not the CAP-induced sensitization. As a check on this assumption, we also examined the effects of the antagonists on eight cells in two experiments without CAP injection.

A second important assumption in these experiments was that the second series of stimuli would evoke approximately the same responses as the first series. Figure $1 A$ shows that this was the case for a cell in which two entire stimulus sequences were given without administration of an EAA antagonist (ACSF was infused through the dialysis fiber). The only substantial change in the responses was an increase in that to PRESS. Figure $1, B$ and $C$, shows two comparable series of responses for other cells, but between the stimulus sequences an EAA antagonist was administered by microdialysis. For Figure $1 B$, the antagonist was CNQX, which selectively blocks non-NMDA receptors, and for Figure $1 C$ it was AP7, which selectively blocks NMDA receptors. In these two experiments, when the EAA antagonist was given, all of the responses were reduced, many profoundly (see below).

Effect of EAA antagonists on responses to EAAs. Figures 2 


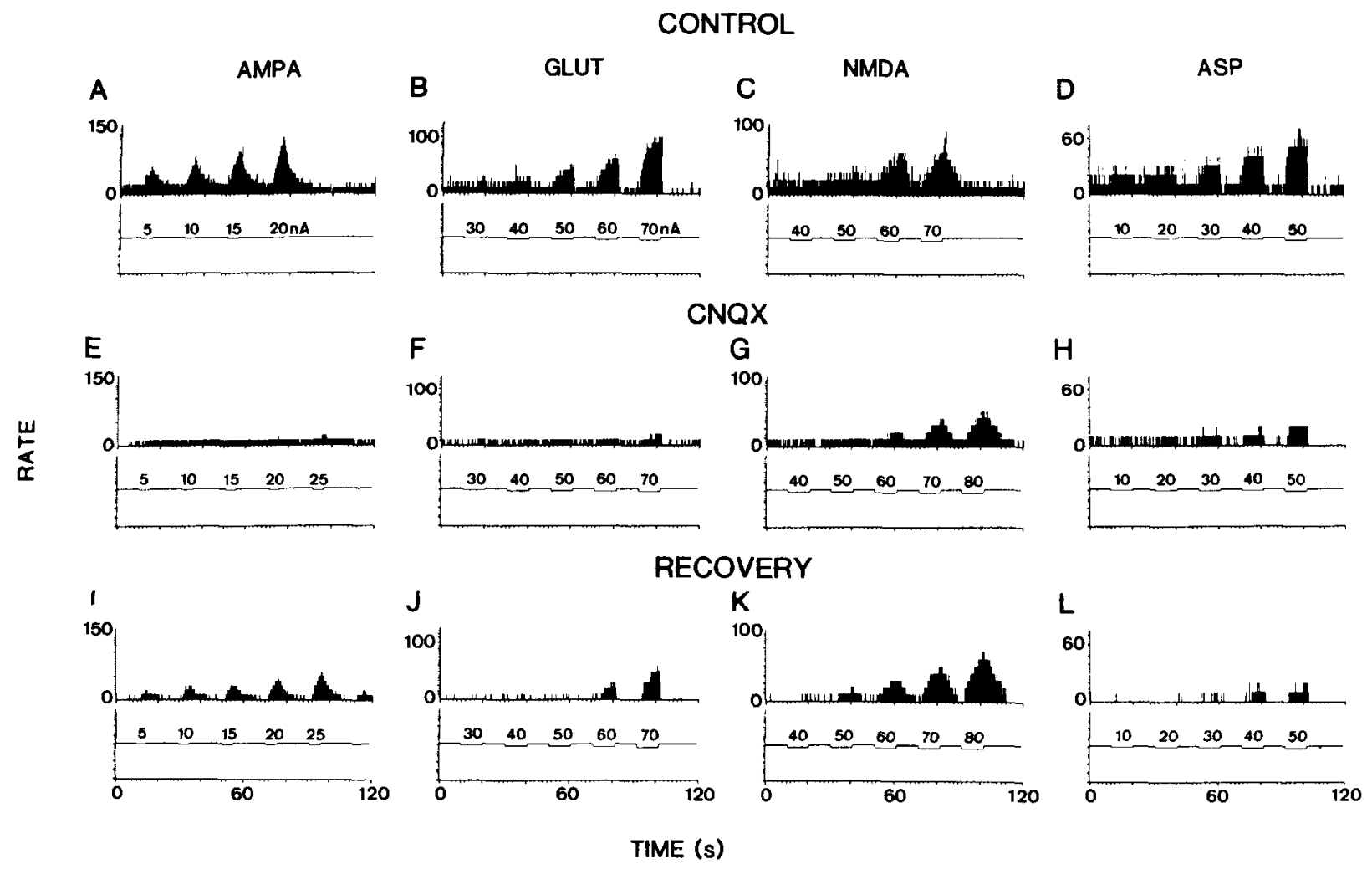

Figure 2. Rate histograms of the responses of a representative WDR STT cell to iontophoretic release of EAAs before, during, and then following dialysis of the spinal cord with CNQX in ACSF. The top row $(A-D)$ shows the control responses of the cell to graded iontophoretic current pulses of AMPA, GLUT, NMDA, and ASP. The second row $(E-H)$ shows the responses of the cell to the EAAs following infusion of CNQX-containing ACSF. Note that for AMPA and NMDA one additional current pulse was delivered during this recording. The bottom row (I-L) shows the responses to the EAAs on partial recovery of the AMPA responses $4 \mathrm{hr}$ after termination of the CNQX and perfusion of the cord with ACSF alone. The responses of this neuron to cutaneous stimulation are illustrated in Figures $1 B$ and 5 . Bin widths are $100 \mathrm{msec}$.

and 3 illustrate the effects of the administration of CNQX and AP7 by microdialysis on the responses of the STT cells that were also shown in Figure $1, B$ and $C$, to various EAAs. Iontophoretic application of all five EAAs resulted in a dose-related activation of each STT cell studied. Perfusion of the spinal cord with the EAA antagonists resulted in a profound suppression of the responses of the neurons to the specific ligands at which the antagonists were directed. For example, in Figure $2 E$, a complete block of the responses to AMPA was obtained $60 \mathrm{~min}$ after starting flow of CNQX-ACSF. The responses to KAIN for this neuron and the remaining representative neurons were comparable to the results with AMPA (data not shown). At the same time at which the responses of the neuron to AMPA were completely blocked, responses to NMDA were still present, although some reduction as shown in Figure $2 G$ was not uncommon. The responses to GLUT were more sensitive to block by CNQX than were the responses to ASP, as shown in Figure 2, $F$ and $H$. Finally, following a washout period of $4 \mathrm{hr}$, the responses to all EAAs showed evidence of recovery toward the baseline level.

Comparable results were obtained following perfusion of the cord with AP7-ACSF. As shown in Figure $3 E$, following $30 \mathrm{~min}$ of infusion of AP7 through the microdialysis fiber, the responses to NMDA were completely blocked while the responses to AMPA showed no apparent change (Fig. $3 G$ ). $\Lambda$ t the time when the responses to NMDA were blocked, the responses to ASP were substantially reduced while those to GLUT appeared to be unaffected (Fig. 3F, $H$ ). Following 2 hr of washout, the responses to NMDA showed evidence of partial recovery (Fig. $3 I$ ), while the responses to the other EAAs had returned to levels that were equal to or greater than those obtained initially.

The averaged responses of all cells exposed to the various EAAs in the presence of either CNQX or AP7 are shown in Figure 4. The effects of the antagonists on the responses to AMPA and KAIN were comparable (Fig. 4A,B). Infusion of AP7 did not result in any significant change in the mean response of the cells to AMPA and KAIN. There was a $20 \%$ reduction in the mean response to GLUT; however, this was not statistically significant. In contrast, CNQX infusion resulted in a nearly complete blockade of the responses to AMPA and KAIN and profoundly reduced the responses to GLUT. Little recovery was seen in the responses to the non-NMDA ligands during the washout of AP7, presumably due to the small initial effects of this antagonist. The recovery of the responses was very slow during washout of CNQX. Often only a partial recovery was seen at 60-180 min after termination of the infusion of this antagonist.

The effects of the antagonists on the responses of the cells to NMDA and ASP were very similar (Fig. $4 D, E$ ). A very large reduction in mean response of the cells was observed after AP7 infusion and only a small reduction with CNQX infusion. In fact, the responses to NMDA were greatly reduced without exception by AP7, while the responses to NMDA in the presence of CNQX showed increases, small decreases, or no obvious change. Finally, the responses to NMDA and ASP after discontinuation of AP7 infusion returned toward baseline levels over a time course that varied widely between individual cases. Dis- 


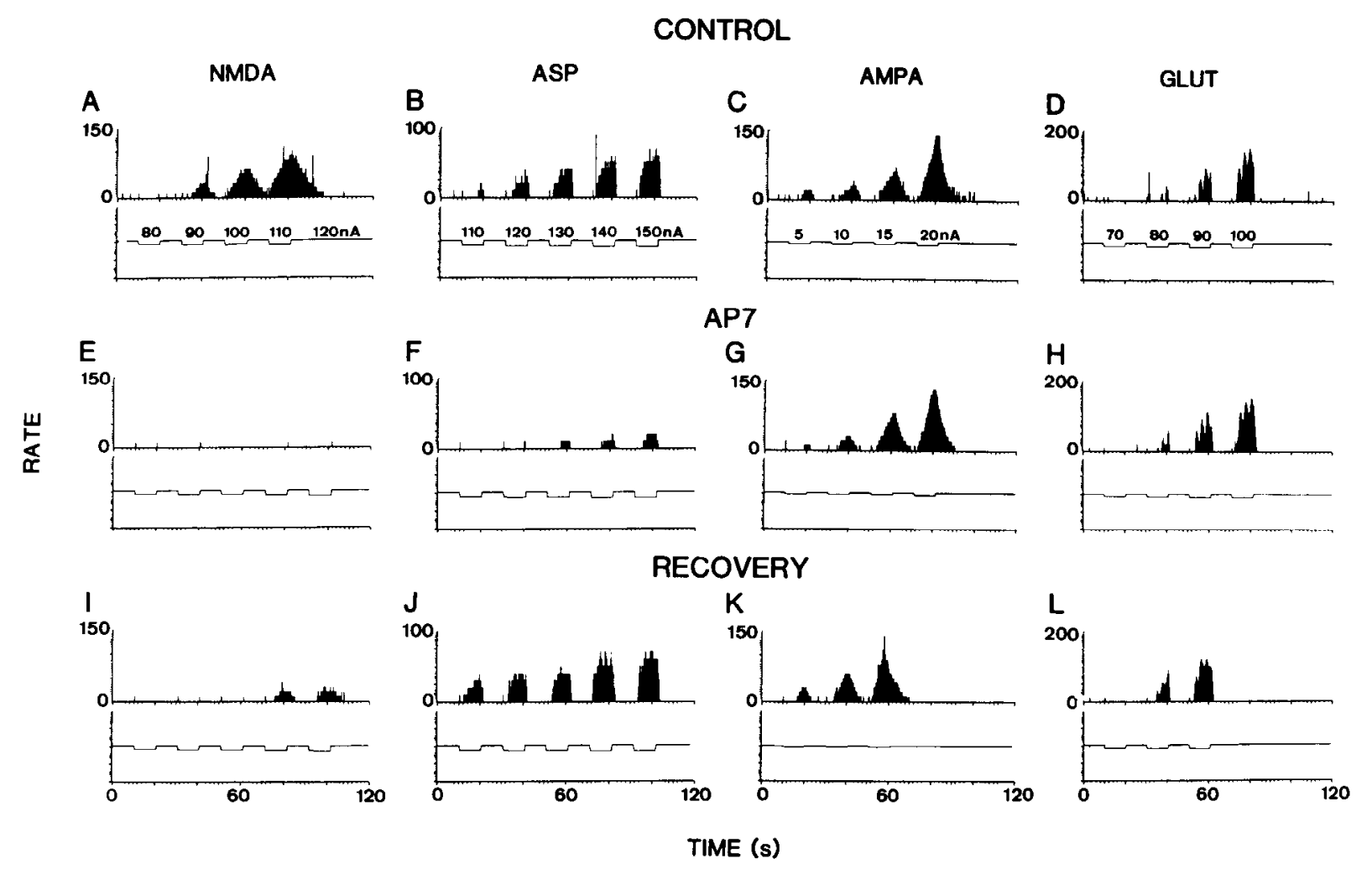

Figure 3. Rate histograms of the responses of a representative WDR STT cell to iontophoretic release of EAAs before, during, and then following dialysis of the spinal cord with AP7 in ACSF. The top row $(A-D)$ shows the control responses of the cell to graded iontophoretic current pulses of NMDA, ASP, AMPA, and GLUT. The second row $(E-H)$ shows the responses of the cell to the EAAs following infusion of the AP7-containing ACSF. Note that for NMDA one additional current pulse was delivered during this recording. The bottom row $(I-L)$ shows the responses to EAAs on partial recovery of the NMDA responses $2 \mathrm{hr}$ after termination of the AP7 and perfusion of the cord with ACSF alone. Note in the bottom row that one less current pulse for AMPA and GLUT was delivered. The responses of this neuron to cutaneous stimulation are illustrated in Figures $1 C$ and 7 . Bin widths are $100 \mathrm{msec}$.

continuation of CNQX had only a small effect on the responses to NMDA and ASP, as expected from the small changes observed in the presence of the antagonist.

Effects of EAA antagonists on background activity and the responses to mechanical stimuli. An example of the background activity and the responses to mechanical stimulation of an STT cell before, during, and after CNQX administration is shown in Figure 5 (see also Figs. $1 B, 2$ ). The cell had clear responses to BRUSH, PRESS, and PINCH at the time of the control recordings (Fig. $5 A-C$ ). The background activity of this cell during the recording of the initial responses to the mechanical stimuli was 9.75 spikes/sec. During infusion of CNQX, when the AMPA responses of the neuron were blocked, the responses to all mechanical stimuli tested were nearly completely abolished (Fig. $5 D-F$ ) and the background activity was reduced to $2.65 \mathrm{spikes} / \mathrm{sec}$ (compare the first $10 \mathrm{sec}$ of the records in $A$ and $D$ ). Following washout of the antagonist and partial restoration of the AMPA responses, the responses to PINCH began to show some recovery, while the responses to PRESS remained greatly reduced and that to BRUSH remained absent.

The responses of two STT cells to mechanical stimulation before and after AP7 infusion are illustrated in Figures 6 and 7. One of these cells (Fig. 6) shows the typical effects of AP7, while the second cell (Fig. 7) shows more dramatic effects that were encountered on occasion. The control responses to mechanical stimulation were readily evident at all five test sites for both neurons (Figs. $6 A-C, 7 A-C$ ). The background activity of the first cell was 14.28 spikes/sec, and that of the second cell was $0.27 \mathrm{spike} / \mathrm{sec}$. Once the AP7 had completely blocked the response to NMDA, the responses to BRUSH and PRESS were essentially unchanged for most STT cells (Fig. $6 D, E$ ) while the responses to PINCH generally showed a small reduction (Fig. $6 F$ ). The background activity of the representative cell also showed little change (compare $A$ to $D$ ), becoming reduced to $13.03 \mathrm{spikes} / \mathrm{sec}$. For the exceptional neuron, when the NMDA responses were abolished (see Fig. 3), the response to BRUSH was also completely inhibited (Fig. 7D). The responses to PRESS and PINCH for this cell also showed some reduction (Fig. 7E,F). Background activity was absent in this cell following infusion of AP7, but was also very low in the control recording (Fig. $7 A$ ). Finally, on partial recovery of the responses of these cells to NMDA, the responses to all mechanical stimuli of the typical neuron and the PINCH response of the exceptional neuron showed evidence of a rebound increase in size (Figs. $6 G-I$, Fig. $7 I$ ), while the BRUSH and PRESS responses of the exceptional neuron had increased to a level less than or near the control.

Effects on grouped background activity and responses to mechanical stimuli. The averaged responses to the mechanical stimuli and the mean background discharge rates of the cells before, during, and following administration of the antagonists are shown in Figure 8. The effects of the antagonists on background activity are shown in Figure $8 \mathrm{~A}$. Comparison of the solid bars with the open bars shows that both antagonists significantly reduced the mean background activity; however, CNQX re- 


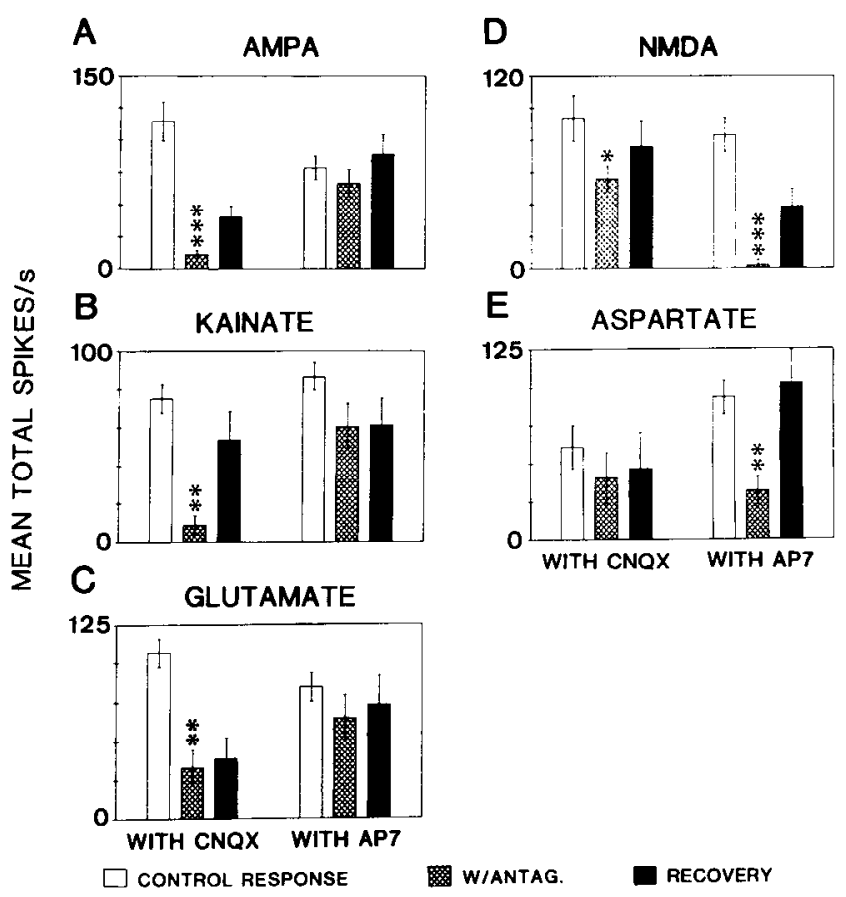

Figure 4. The bar graphs summarize the group means (and SEs) for the total number of spikes above background evoked by all iontophoretic current pulses for each EAA tested. Comparisons between responses at different times of the experiments used the same series of pulses as in the control recording. The open bars show the control value, the crosshatched bars show the mean response with antagonist present, and the solid bars show the mean responses following washout of the antagonist. The responses with CNQX present are at the left of each panel, and those with AP7 are at the right. ${ }^{*}, p<0.05 ;{ }^{* *}, p<0.01 ;{ }^{* * *}, p<$ 0.001 . sulted in a more significant $(p<0.01)$ reduction than did AP7 $(p<0.05)$. Following the washout period, the background activity of the AP7-treated cells tended to show a rebound increase while that of the CNQX-treated cells remained depressed.

The effects of the antagonists on the averaged BRUSH responses are shown in Figure $8 B$. AP7 did not result in a reduction of the mean BRUSH response, although it did cause a reduction of BRUSH responses of some individual cells (Figs. 1C, 6G). The mean response to BRUSH in the CNQX group was significantly reduced $(p<0.01)$. Hours following discontinuation of infusion of the antagonist, recovery of the responses to the EAAs resulted in a rebound increase of the BRUSH response in the AP7-treated cells, whereas the responses of the CNQXtreated cells remained greatly reduced even though the responses to AMPA had shown some evidence of recovery.

The grouped responses to PRESS are shown in Figure $8 C$. Infusion of AP7 again did not result in a reduction of the mean response. In contrast, infusion of CNQX resulted in a significant reduction in the mean PRESS response $(p<0.01)$. Discontinuation of the AP7 infusion again resulted in a rebound increase of the PRESS response following a washout period, while termination of the CNQX infusion resulted in only a small increase in PRESS response despite several hours of washout.

The grouped PINCH responses are shown in Figure $8 D$. Infusion of AP7 resulted in a small but significant reduction in mean response to PINCH $(p<0.05)$. Infusion of CNQX alsn resulted in a significant reduction in the $\mathrm{PINCH}$ response when compared to the control level $(p<0.01)$, and this was of a much larger magnitude than the reduction obtained with AP7. Discontinuation of the antagonists once again resulted in a rebound
BRUSH
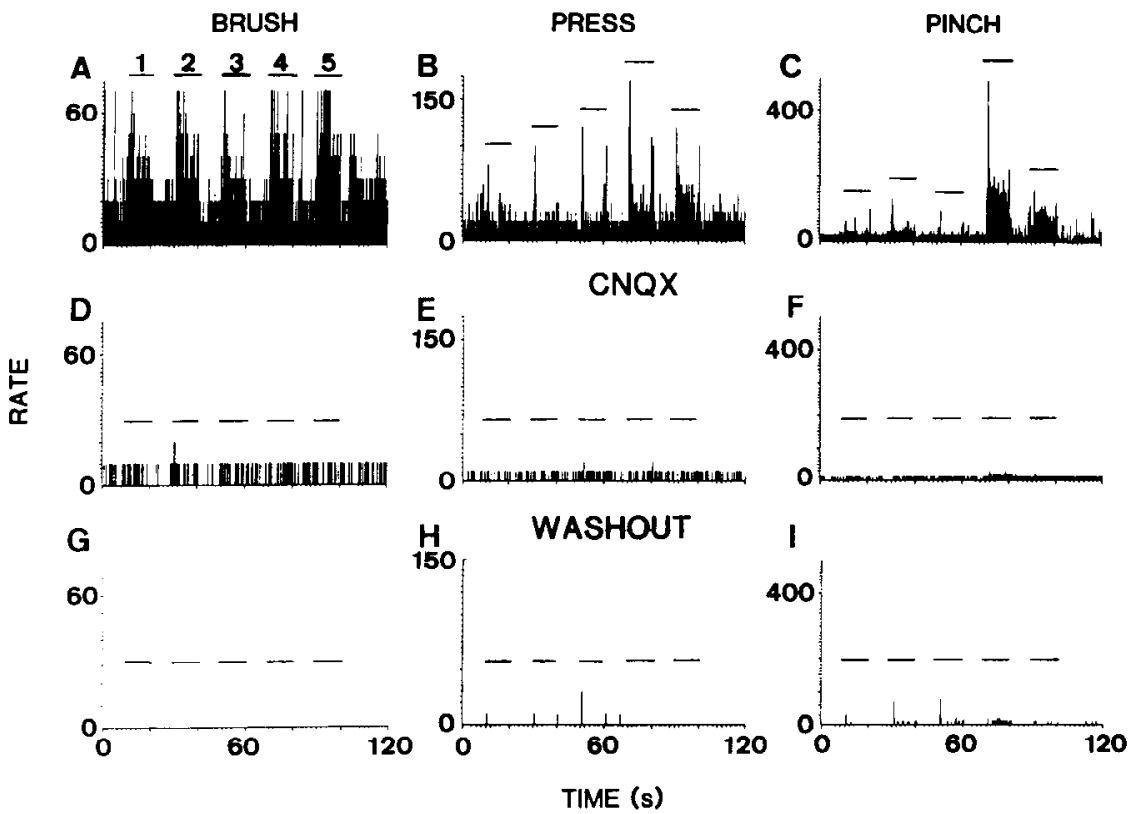

\section{CONTROL}

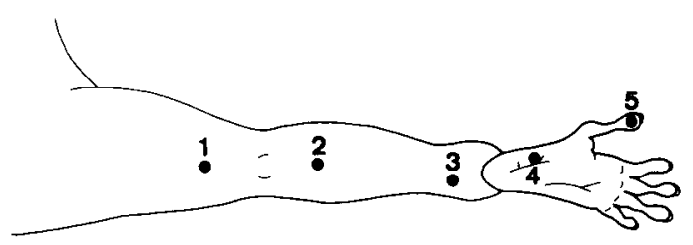

Figure 5. Rate histograms of the responses of a representative WDR STT ccll to mechanical stimulation of the skin before, during, and then following infusion of the spinal cord with CNQX in ACSF. The top row $(A-C)$ shows the control responses of the cell to BRUSH (left column), PRESS (center column), and PINCH (right column). The second row $(D-F)$ shows the responses of the cell during infusion of the CNQX-containing ACSF. The bottom row $(G-I)$ shows the responses on partial recovery of the AMPA responses of this cell (also illustrated in Figs. 1, 2) $4 \mathrm{hr}$ after termination of the CNQX and perfusion of the cord with ACSF alone. The sites for application of the stimuli are marked upon the drawing of the leg at the bottom of the figure, and the times of application at each site are identified by the solid horizontal bars toward the top of each histogram. Bin widths are 100 msec. 
Figure 6. Ratc histograms of the responses of a representative WDR STT cell to mechanical stimulation of the skin before, during, and then following infusion of the spinal cord with AP7 in ACSF. The top row $(A-C)$ shows the control responses of the cell to BRUSH (left column), PRESS (center column), and PINCH (right column). The second row $(D-F)$ shows the responses of the cell during infusion of the AP7-containing ACSF. The bottom row $(G-I)$ shows the responses on partial recovery of the NMDA responses of this cell 3 hr after termination of the AP7 and perfusion of the cord with ACSF alone. Note the rebound increase in the responses to the BRUSH and PINCH stimuli. The sites for application of the stimuli are marked on the drawing of the leg at the bottom of the figure, and the times of application at each site are identified by the solid horizontal bars toward the top of each histogram. Bin widths are $100 \mathrm{msec}$.

Figure 7. Rate histograms of the responses of a WDR STT cell to mechanical stimulation of the skin before, during, and then following infusion of the spinal cord with AP7 in ACSF to illustrate an unusual case in which the responses to innocuous stimuli were reduced. The top row $(A-C)$ shows the control responses of the cell to BRUSH (left column), PRESS (center column), and PINCH (right column). The second row $(D-F)$ shows the responses of the cell during infusion of the AP7-containing ACSF. The bottom row $(G-I)$ shows the responses on partial recovery of the NMDA responses of this cell (see also Figs. $1 C, 3) 4 \mathrm{hr}$ after termination of the AP7 and perfusion of the cord with ACSF alone. The sites for application of the stimuli are marked on the drawing of the leg at the bottom of the figure, and the times of stimulus application at each site are identified by the solid horizontal bars in each histogram. Bin widths are $100 \mathrm{msec}$.
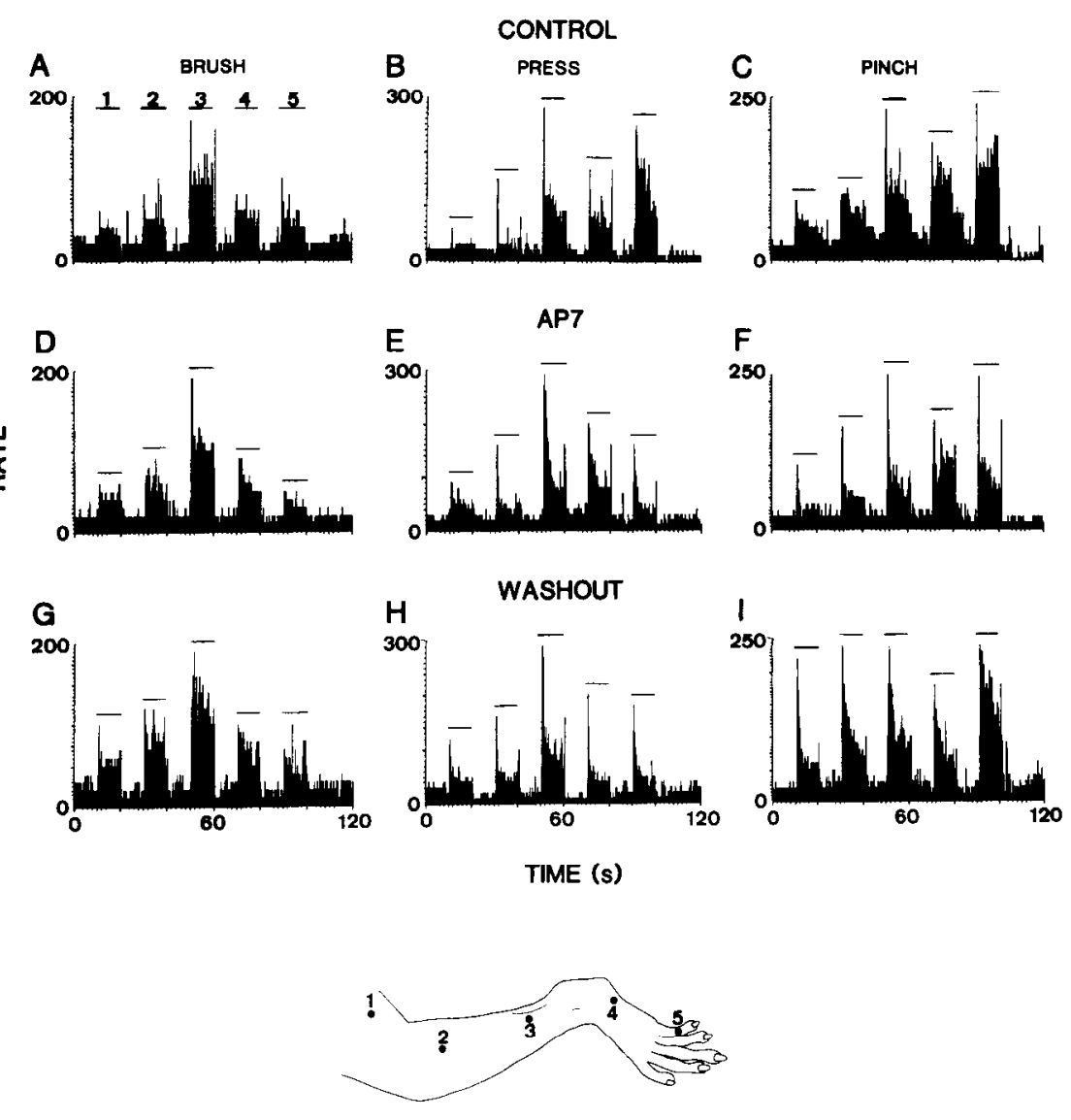

BRUSH
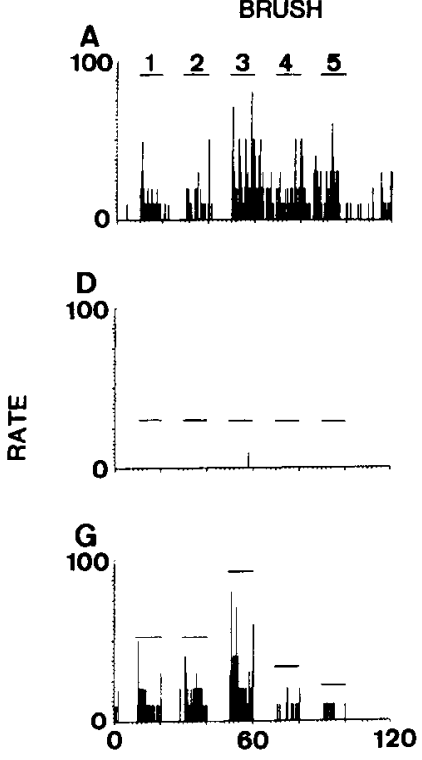

CONTROL

B

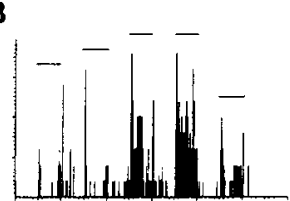

C

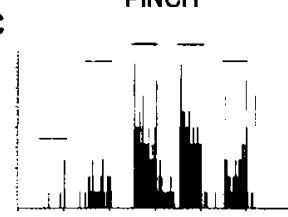

E

AP7
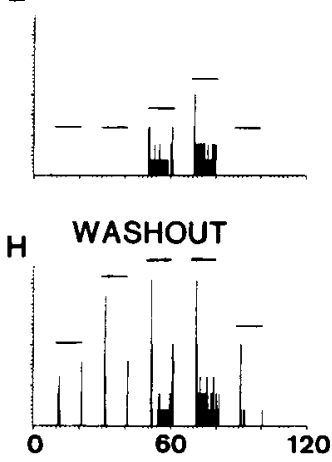

F

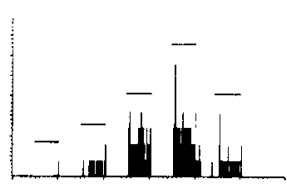

I

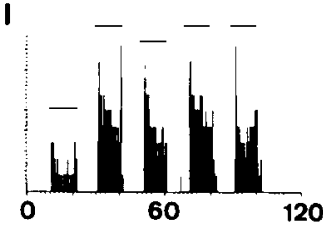

TIME (s)

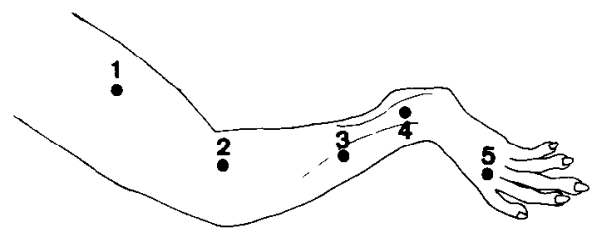




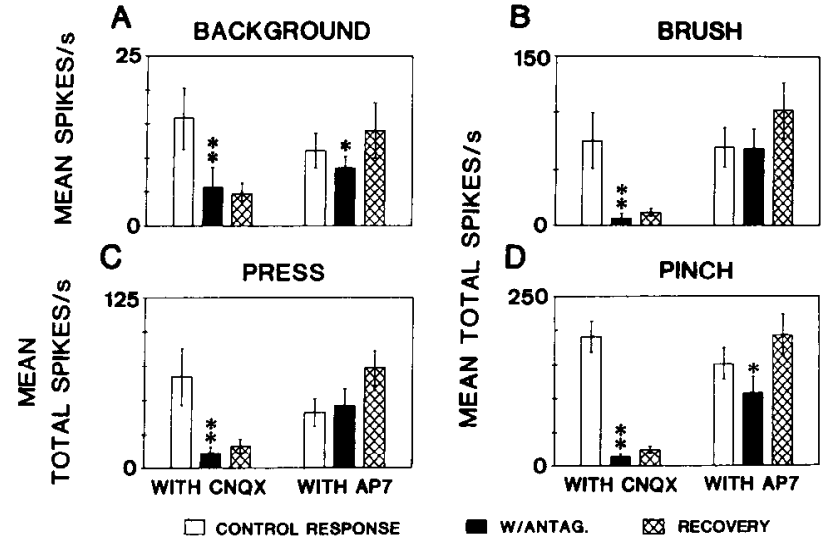

Figure 8. The bar graphs summarize the group mean (and SE) background activity and the mean (and SE) for the total number of spikes above background evoked from all five sites on the skin for each of the mechanical stimuli for those STT cells in animals stimulated by intradermal CAP. The open bars show the control valucs; the solid bars, the mean responses with antagonist present; and the crosshatched bars, the mean responses following washout of the antagonist. The responses with CNQX present are at the left of each panel, and those with AP7 are at the right. ${ }^{*}, p<0.05 ;{ }^{* *}, p<0.01$.

increase in response for the AP7-treated cells and only a very small recovery in response for the CNQX-treated cells.

To ensure that our results were not grossly affected by the intradermal administration of CAP, two additional experiments were performed to assess the effects of CNQX and AP7 on the responses of STT cells to the mechanical stimuli without an intervening injection of the chemical stimulant. The combined results for the eight cells included in this subgroup (three for CNQX and five for AP7) are shown in Figure 9. The results obtained with both antagonists were essentially identical for the groups of cells that were not activated by CAP as for those that were. The background activity and the responses to BRUSH, PRESS, and PINCH were all greatly reduced during infusion of CNQX and blockade of the responses of the cell to iontophoretically released AMPA. The background activity and the responses to the mechanical stimuli showed little recovery following a washout period and partial restoration of the responses to AMPA. Cells exposed to AP7 without CAP showed a small reduction in background activity, no change in the responses to either BRUSH or PRESS, and only a small reduction in the responses to PINCH. Following a washout period and partial restoration in the responses of these cells to NMDA, a significant rebound increase was observed for the responses to BRUSH and PRESS, while the responses to PINCH showed no obvious change from the level observed during infusion of the AP7.

Effects of EAA antagonists on responses to chemical stimulation. Figure 10 shows the responses of two representative neurons to the chemical stimulation of $\mathrm{C}$ afferents produced by intradermal CAP injection. The CNQX-treated cell (Fig. 10 A$D)$ had a steady background discharge of 2.1 spikes/sec when the control recording was made (Fig. 10A). The first injection of CAP within the receptive ficld resultcd in a very large increase in discharge frequency that attained a peak of nearly 200 spikes/ sec (67.3 spikes/sec averaged over $20 \mathrm{sec}$; Fig. 10B). This large elevation was followed by a new elevated background discharge rate of 5.9 spikes/sec, which persisted for at least 15 min after injection. The infusion of CNQX and establishment of a blockade of the responses to AMPA were accompanied by a reduction

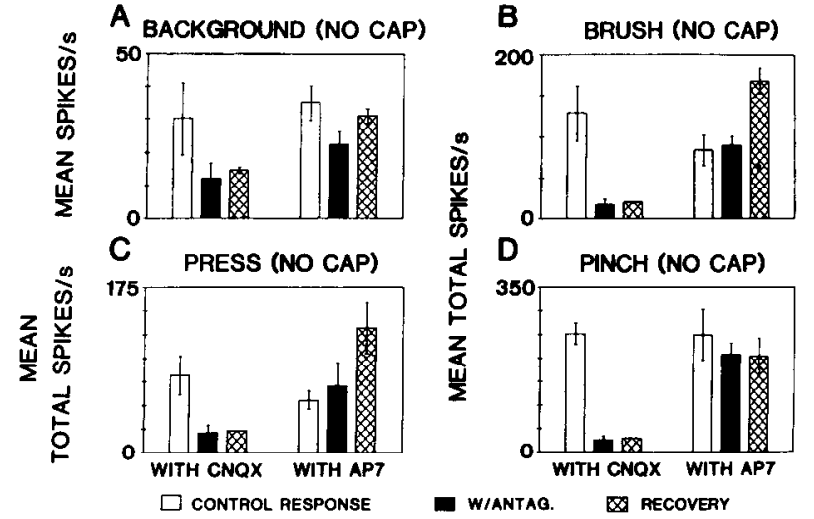

Figure 9. The bar graphs summarize the group mean (and SE) for the total number of spikes above background evoked from all five sites on the skin for each of the mechanical stimuli in animals not given intradermal CAP injections. The open bars show the control values; the solid bars, the mean responses with antagonist present; and the crosshatched bars, the mean responses following washout of the antagonist. The responses with CNQX present are at the left of each panel, and those with AP7 are at the right. Statistics were not calculated because the cell numbers were small in these groups.

in the background activity of this cell to a mean rate of 0.58 spike/sec (Fig. 10C). A second injection of CAP at a slightly more proximal site in the receptive field resulted in no substantial increase in activity (Fig. 10D), in contrast to the large increase seen with the first injection. In addition, although a small sustained background discharge of 2.83 spikes/sec was observed, the magnitude of this discharge was much smaller than that following the first injection.

The AP7-treated cell showed less dramatic changes than those of the CNQX-treated cell (Fig. 10E-H). The initial background discharge rate of this cell was 22.4 spikes/sec (Fig. 10E). The first injection of CAP resulted in a large initial burst of activity that attained a peak of nearly 300 spikes/sec ( 70.9 spikes/sec averaged over $20 \mathrm{sec}$ ), followed by a slowing of the rate to a new sustained level of 30.5 spikes/sec (Fig. 10F). Upon infusion of AP7 and establishment of a blockade of the responses to NMDA, the background discharge rate was reduced to 12.6 spikes/sec (Fig. 10G). The second injection of CAP resulted in a greatly attenuated initial burst of activity to less than 150 spikes/sec ( 45.4 spikes/sec averaged over $20 \mathrm{sec}$ ) and a sustained discharge rate of 14.58 spikes/sec (Fig. $10 H$ ).

Grouped responses to $C A P$ and $C A P$-induced sensitization. The averaged effects of the antagonists on the responses to chemical stimulation by CAP are summarized in Figure 11. Figure $11 \mathrm{~A}$ shows the effects of both antagonists on the burst in activity of the cells observed immediately (averaged over the first 20 sec) after injection of CAP. In both the CNQX-and AP7-treated groups, following the first CAP injection the cells showed a large mean increase in activity of approximately 50 spikes/sec (averaged over $20 \mathrm{sec}$ ) above the resting background discharge rate. The second CAP injection resulted in a greatly blunted surge in activity for the AP7-treated cells $(p<0.05)$, while infusion of CNQX totally prevented this increase $(p<0.001)$.

Previous work has shown that following intradermal injection ofCAP, a transient sensitization of the responses of STT neurons to mechanical stimulation may be produced (Simone et al., 1991; Dougherty and Willis, 1992). One criterion used to define the induction of sensitization of STT cells by CAP was a sus- 


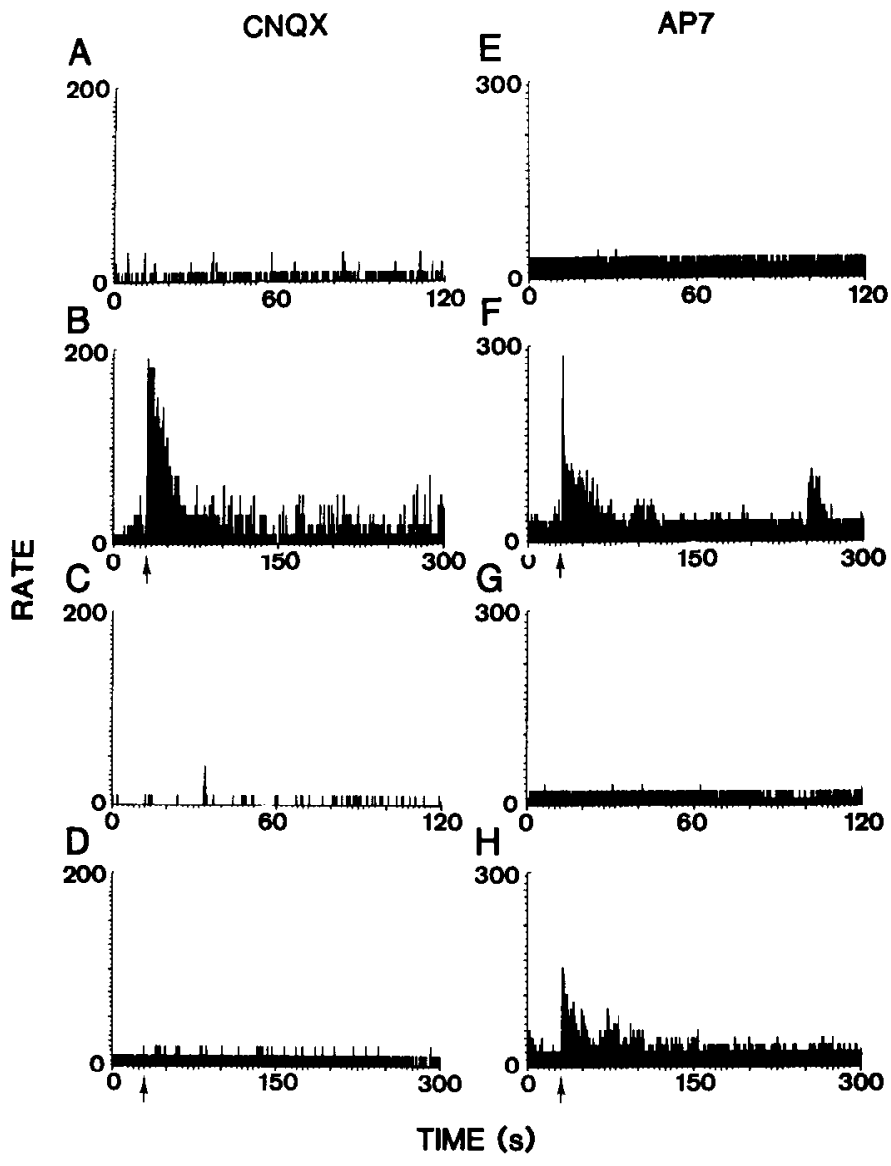

Figure 10. Rate histograms of two representative WDR cells showing the background activity and control responses to intradermal CAP before and then with CNQX (left column) or AP7 present (right column). The top row shows the initial background discharge prior to CAP injection. The second row shows the responses to the first CAP injection (at arrow; note change in time scale). The third row shows the background discharge rate after infusion of the antagonists and establishment of receptor blockade as cvidenced by a lack of response to AMPA for the CNQX-treated cell or NMDA for the AP7-treated cell. The bottom row shows the background discharge rate following the second injection of CAP (at arrow; again, note change in time scale). The neurons shown in this figure are the same as those in Figures $1, A$ and $B ; 2 ; 3 ; 5$; and 7. Bin widths are again $100 \mathrm{msec}$.

tained increase in background activity of the STT neurons lasting at least $15 \mathrm{~min}$ after the injection. The effects of the antagonists on the ability of the CAP injection to produce a sustained increase in background activity are shown in Figure $11 \mathrm{~B}$. The background activity of the neurons in both groups recorded over a 2 min period starting 15 min after the first injection of CAP (dark crosshatched bars) showed a significant ( $p<0.01$ for the AP7-treated group and $p<0.05$ for the CNQX-treated group) elevation over the original control discharge rate (open bars). In contrast, during administration of the antagonists, neither group showed a significant increase in background activity 15 min after the second CAP injection (light crosshatched bars) compared to the background rate just before the second injection (solid bars).

A sccond critcrion for sensitization was enhancement of the responses of the STT cells to mechanical stimulation of the skin (Simone et al., 1991; Dougherty and Willis, 1992). Figure 11C$E$ shows the effects of the antagonists in preventing the enhancement of the responses of STT cells to mechanical stimu- lation often observed after CAP injection. The mean responses of the cells in both treatment groups to BRUSH and PRESS following the first injection of CAP (dark crosshatched bars) were significantly elevated ( $p<0.05$ for both) above the control levels (open bars), while the mean responses to $\mathrm{PINCH}$ after CAP were not significantly different than control. Thus, the averaged responses of the cells in both the AP7- and CNQXtreated groups showed evidence of sensitization after the first injection of CAP similar to that previously shown for other STT neurons (Simone et al., 1991; Dougherty and Willis, 1992). In contrast, with the antagonists present, no increases in mean responses to BRUSH, PRESS, or PINCH were observed after the second injection of CAP (light crosshatched bars compared to solid bars).

Grouped thermal responses. The mean responses of STT cells to thermal stimulation before and then during infusion of the antagonists are shown in Figure 12. The results for the cells exposed to the effects of CAP stimulation are shown in Figure $12 A$, and Figure $12 B$ shows the results for cells in animals not given CAP injections. The open symbols show the control response curves for each group (circles for AP7-, squares for CNQXtreated cells). The threshold for response to a $5 \mathrm{sec}$ heat pulse was between $45^{\circ} \mathrm{C}$ and $49^{\circ} \mathrm{C}$ for both groups exposed to CAP stimulation. Following stimuli above threshold, the responses increased in an approximately exponential fashion with increasing temperature across the range tested. The thermal responses obtained following blockade of NMDA receptors with AP7 are shown by the curve with solid circles. The threshold was now between $49^{\circ} \mathrm{C}$ and $51^{\circ} \mathrm{C}$, but the curve above threshold showed an exponential rise. Hence, the AP7 caused a rightward shift of the thermal response curve. Finally, the response curve in the presence of CNQX blockade of non-NMDA receptors is that with the solid squares. CNQX resulted in a nearly complete block of the responses to noxious heat.

The results for cells in animals not exposed to CAP (Fig. 12B) were nearly identical to those from animals that were exposed. Control threshold for the AP7-treated cells was between $45^{\circ} \mathrm{C}$ and $47^{\circ} \mathrm{C}$, and the response curve then rose steeply over the higher intensity range. Following infusion of AP7, the threshold for these cells shifted to near $49^{\circ} \mathrm{C}$, followed by a steep rise over the rest of the response range. Hence, with or without exposure to CAP stimulation, AP7 appears to result in an elevated threshold and often a rightward shift of the thermal response curve. The threshold for control responses of the CNQX-treated cells was also between $45^{\circ} \mathrm{C}$ and $47^{\circ} \mathrm{C}$. Infusion of CNQX abolished the responses of these cells to thermal stimulation.

Responses to electrical stimulation of a dorsal rootlet. Volleys were evoked in a dorsal root filament by graded intensities of electrical stimuli from just above threshold $(0.2-1.0 \mathrm{~V})$ to 10 times threshold. Stimuli at these intensities would presumably activatc myelinated fibers ranging in size from the largest down into the A $\delta$ range; however, the smallest myelinated and unmyelinated fibers would not have been excited. The responses that were recorded included the negative cord dorsum potentials, the local negative field potential that was detected by the microelectrode used to record the activity of the STT cell under observation, and the discharges of the STT cell.

Figure 13 shows tracings of the negative cord dorsum and local field potentials in the same experiment in which recordings were made from the neurons shown in Figures $1, A$ and $C ; 2$; 3 ; and 7. In Figure $13 A$, the superimposed records are the cord dorsum potentials evoked by stimuli that were near threshold 


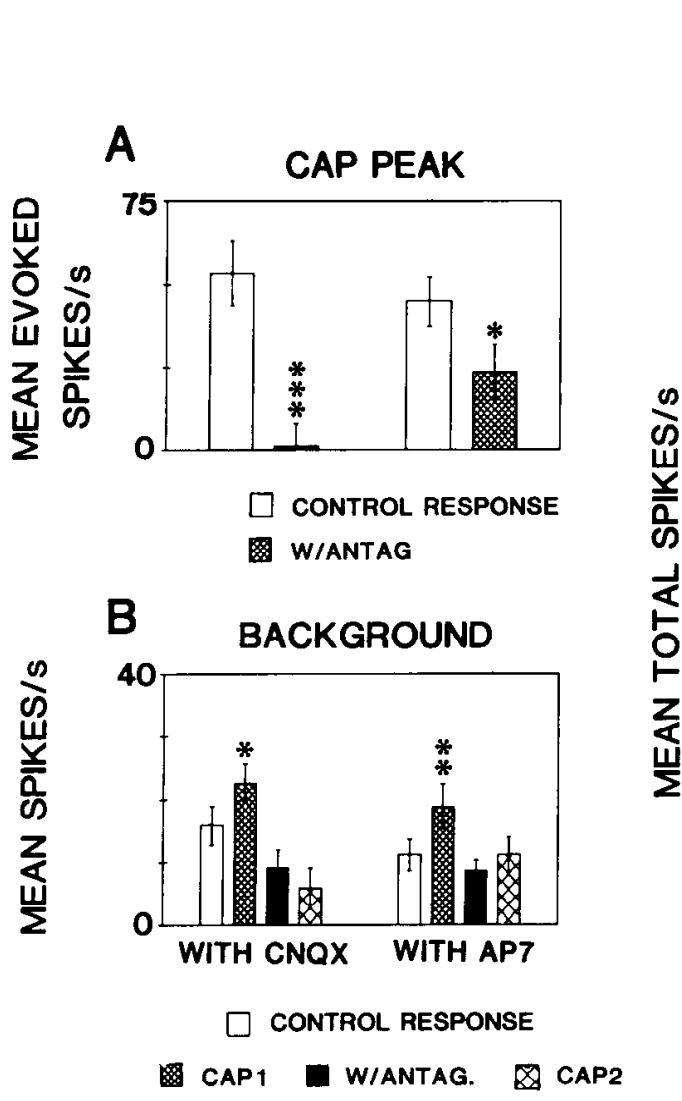

C
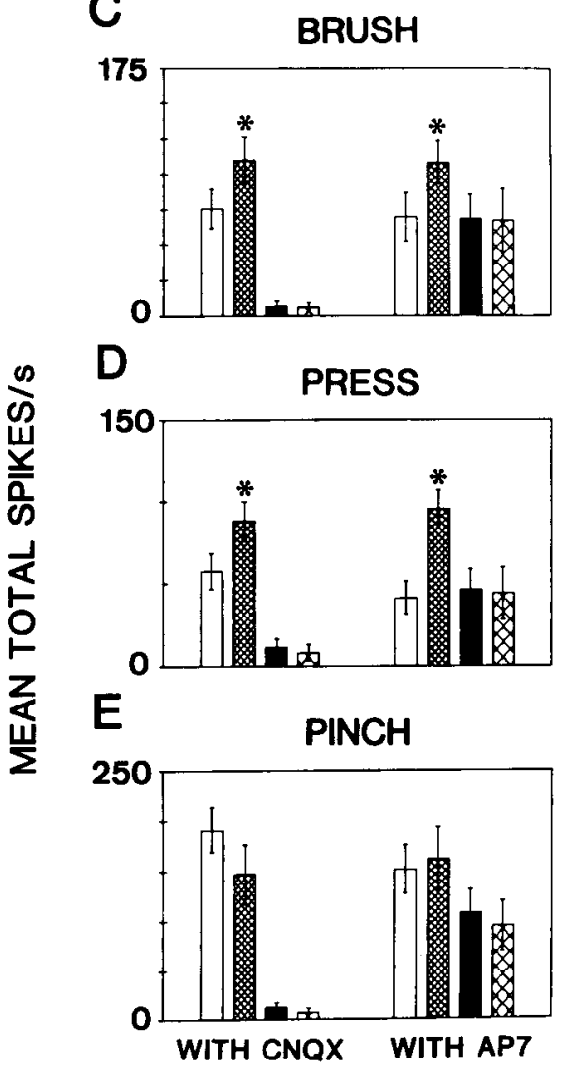

Figure 11. The bar graphs summarize the averaged responses of the cells in the AP7- and CNQX-treated groups to CAP. $A$ shows the mean spikes above background evoked during the first 20 sec after injection of CAP. The open bars show the control values for each group, and the crosshatched bars, the values for the second injection of CAP while the antagonists were present. $B$ shows the background activity before and then $15 \mathrm{~min}$ after each CAP injection, while $C-E$ show the BRUSH, PRESS, and PINCH responses before and after each of the CAP injections. The initial baseline values are shown by the open bars; the responses after the first CAP injection, by the dark crosshatched bars; the responses prior to the second CAP injection with antagonist present, by the solid bars; and the responses after the second CAP injection, by the light crosshatched bars. ${ }^{*}, p<$ $0.05 ; * *, p<0.01 ; * * *, p<0.001$. Note that the baseline values and the values with the antagonist present for $B-E$ are the same as those shown by the corresponding (open and solid) bars in Figure 8 .
(T) and $2 T, 4 T$, and $10 T$ for axons in the dorsal root filament. The increasingly larger volleys evoked progressively larger $\mathbf{N}$ waves. During the infusion of CNQX, the same volleys evoked much smaller $\mathrm{N}$ waves (Fig. $13 B$ ). In Figure $13 E$, the same dorsal rootlet volleys are shown to evoke a negative field potential in the vicinity of the STT cell under observation. The higher-intensity volleys also caused a burst discharge by the STT cell. During administration of CNQX, the negative field potential was nearly eliminated (although the afferent volley was still present), and the cell did not discharge in response to the largest volley (Fig. 13F). Administration of AP7 was less effective in reducing the negative cord dorsum and field potentials. In Figure 13, $C$ and $D$, the negative cord dorsum potentials were only slightly reduced by AP7. The local field potential was more affected than the cord dorsum potential, as seen in Figure 13, $G$ and $H$; the discharges evoked by the volleys at $2 T, 4 T$, and $10 T$ were reduced in number but not eliminated by AP7.

The changes in the mean negative cord dorsum potentials, negative field potentials, and evoked discharges of the STT cells produced by administration of CNQX or AP7 for both treatment groups are summarized in Figure 14. The bar graph in Figure $14 \mathrm{~A}$ shows the mean total evoked responses, and the line graphs in Figure $14 B-D$ show the mean responses at each stimulus strength. Both CNQX and AP7 produced significant reductions ( $p<0.001$ and $p<0.05$, respectively) in the total number of spikes evoked by the graded electrical volleys. However, by comparison the grouped responses for the CNQX-treated cells showed much larger reductions than did the AP7-treated cells. The relative potency of CNQX versus AP7 in reducing the electrically evoked responses is further evidenced by the bar and line graphs for the spinal cord potentials. AP7 did result in a significant reduction $(p<0.05)$ in the size of the local field potentials but not in the size of the cord dorsum potentials. In contrast, CNQX resulted in a significant reduction of the field $(p<0.001)$ and cord dorsum $(p<0.01)$ potentials.

Examination of the stimulus-response curves in Figure $14 B$ $D$ shows the relative effects of AP7 and CNQX at each stimulus strength. AP7 resulted in a significant reduction of the evoked spikes at $2-10$ times threshold stimuli $(p<0.05,0.05$, and 0.01 , respectively), and in a significant reduction in the local field potential areas at threshold and 10 times threshold $(p<0.05$ for both). AP7 did not significantly affect the cord dorsum potential areas at any of the stimulus strengths used. In contrast, CNQX resulted in a significant reduction of the evoked spikes, local field, and cord dorsum potential areas at all strengths with $p$ values ranging from $<0.05$ to $<0.01$.

Summary of effects of $C N Q X$ and $A P 7$. Figure 15 summarizes the percentage reduction induced by CNQX and AP7 for responses to each of the EAAs and to all the test stimuli. The $100 \%$ level is the control response level, and the bars show the percentage of control for each stimulus with one or the other antagonist present. The bar graph in Figure $15 \mathrm{~A}$ shows the mean percentage of control for each of the responses induced by the EAAs in the presence of the antagonists. AP7 resulted in a $>90 \%$ reduction of the NMDA response with no change in the response to AMPA. The responses to the endogenous ligand ASP were markedly reduced by AP7, and the responses to GLUT were less affected. CNQX resulted in a $>90 \%$ reduction of the AMPA response and no reduction in the response to NMDA. In contrast to AP7, CNQX resulted in a greater reduction in the response to GLUT but no change in that to ASP. Inspection of the bar graphs in Figure $15 B$ shows that AP7 had no effect on the 


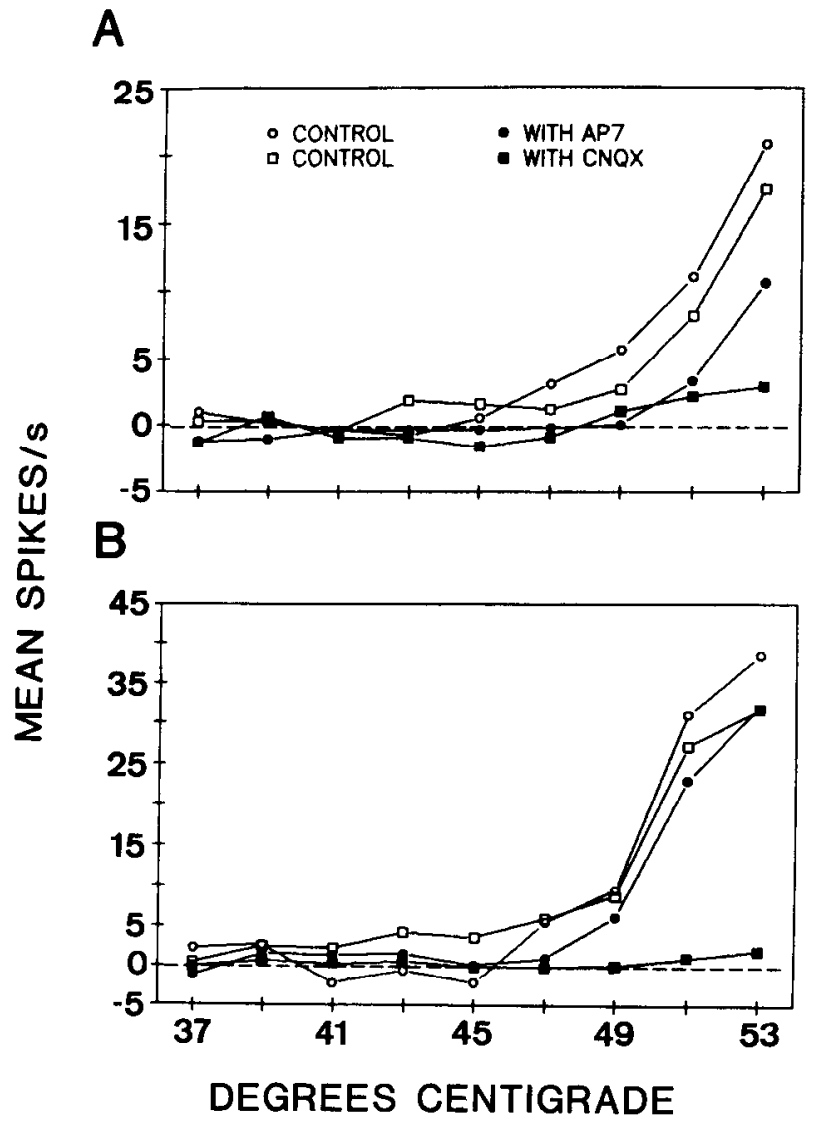

Figure 12. Line graphs show the mean responses of the cells in each group to the thermal stimulus series. The controls are shown by the open symbols; the data from the AP7-treated cells, by circles; and from the CNQX-treated cells, by squares. The solid symbols are the responses for each group (circles for AP7, squares for CNQX) after infusion of the antagonists and blockade of the appropriate EAA responses. $A$ shows the results for those cells also exposed to intradermal CAP, and $B$ shows the results for those cells not exposed to CAP.

responses to BRUSH and PRESS. However, it reduced the responses to PINCH, CAP, and noxious heat to $79 \%, 61 \%$, and $29 \%$, respectively. It also reduced the responses to volleys in myelinated fibers to about two-thirds of the control level. In contrast, CNQX resulted in a reduction of the responses to mechanical, chemical, and thermal stimuli to lcss than $15 \%$ of control, and the responses to the electrical stimuli were reduced to between $25 \%$ and $30.5 \%$ of control.

\section{Discussion}

The present experiments have shown that EAA antagonists may be successfully delivered by microdialysis into the neuropil surrounding an STT neuron to block receptors activated by iontophoretic release of EAA agonists. Although the actual concentrations of the antagonists in the vicinity of the STT cells are not known, we have found empirically that a concentration sufficient to block the responses to receptor-specific agonists can be achieved. This blockade is reproducible and is relatively specific to a targeted receptor. The reduction of the responses to AMPA by AP7 and to NMDA by CNQX were small, generally less than $20 \%$. Although this observation suggests that there may have been some nonspecific antagonism, we cannot exclude the possibility that the cells may have become less excitable because of removal of a tonic excitatory drive since both
AP7 and CNQX could reduce background activity. We also observed that the antagonism produced by AP7 was readily reversed very shortly following discontinuation of its administration, while the antagonism produced by CNQX required a very prolonged washout period for evidence of recovery toward baseline. Investigators using these antagonists in other systems, including in vitro slice preparations, have encountered the same problems in reversing the effects of CNQX (Rainnie et al., 1991). We suspect that this difference in recovery time reflects a difference in the lipid solubility of the two compounds. We conclude that microdialysis provides a convenient method to deliver antagonists in pharmacologically specific doses to a large portion of the dorsal horn.

It is of interest that reductions in GLUT responses were more pronounced with infusion of CNQX than of AP7, while the opposite was true for responses to ASP. This suggests that in the monkey spinal cord, GLUT acts as a non-NMDA-preferring ligand and ASP acts as an NMDA-preferring ligand. This conclusion is consistent with previous proposals based on studies on cat and rat spinal cord (Davies and Watkins, 1983; Jahr and Jessell, 1985; Davies and Lodge, 1987; Davies, 1988; Monaghan et al., 1989).

Our results have also shown that antagonists of EAAs acting on NMDA and non-NMDA receptors reduce the responses of STT neurons to mechanical, chemical, and thermal stimulation of the skin, and to electrical stimulation of dorsal rootlets. These findings further confirm a role for EAAs in the chemical transmission of afferent information to dorsal horn neurons. The responses of STT cells to BRUSH are presumably evoked by volleys in myelinated (A $\beta$ or $\mathrm{A} \delta$ ) fibers (Perl, 1968; Willis et al., 1975), whereas the responses to PINCH would be expected to have been evoked by small myelinated $(\mathrm{A} \delta)$ and unmyelinated (C) fibers. A reduction in the mean responses of the STT cells to BRUSH by CNQX and not by AP7 suggests that chiefly nonNMDA receptors mediate the responses of STT cells to innocuous mechanical stimulation of the skin. However, AP7 did cause a reduction in discharges evoked by electrical stimulation of the dorsal rootlets at intensities sufficient to activate only myelinated afferents, and in addition, a few isolated cells (see Fig. 6) did show a reduction of BRUSH response in the presence of AP7. These additional observations indicate that although non-NMDA receptors are the dominant ones for activation of STT cells by innocuous stimuli, under certain conditions NMDA rcceptors may also transmit information related to innocuous stimuli to STT cells (see below, re sensitization).

Unlike the responses to BRUSH, the mean responses of STT cells to PINCH were reduced by both CNQX and by AP7, suggesting that mechanical nociceptors activate STT cells by a pathway that makes use of both non-NMDA and NMDA receptors. Similarly, the excitation of STT cells by noxious heat stimuli and by intradermal CAP, which are likely to involve activation of thermal nociceptors and chemosensitive $C$ fibers (Baumann et al., 1991), was also reduced by CNQX as well as by AP7. Thus, the responses of STT cells to stimuli conveyed through finely myelinated and unmyelinated afferents involve pathways using both EAA receptor subtypes.

The relative efficacies of CNQX and AP7 in antagonizing the responses of STT cells to cutaneous stimuli, as shown in the present study, would seem to suggest that non-NMDA receptors indeed mediate responses of STT cells following activation of large afferents while NMDA receptors mediate the responses of STT cells following activation of small afferents. However, our 
CORD DORSUM
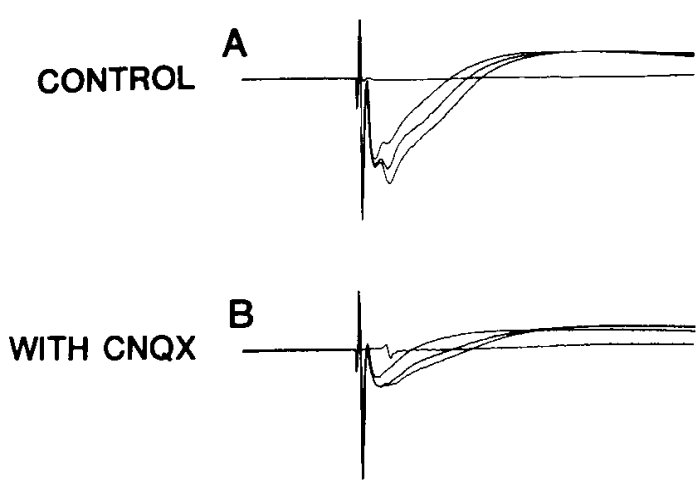

CONTROL

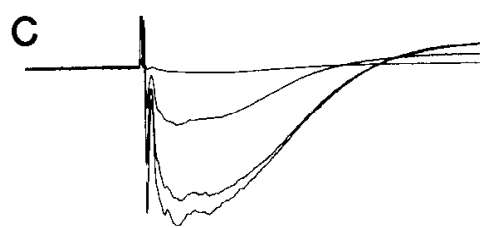

WITH AP7

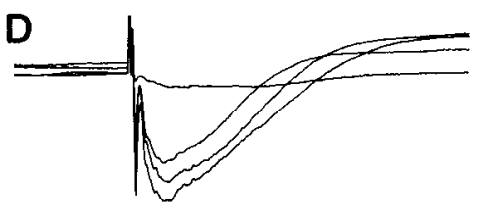

\section{LOCAL FIELD}

E
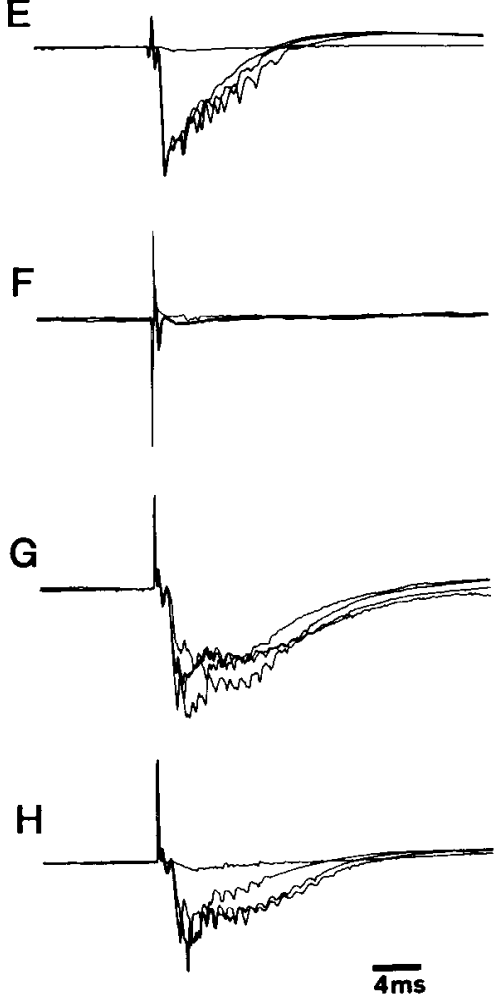

Figure 13. Representative tracings of the cord dorsum (left column) and local field potentials (right column) of two STT ncurons evoked by dorsal root stimulation before and then after infusion of CNQX $(A, B$ and $E, F)$ or AP7 $(C, D$ and $G, H)$. The responses to all stimuli are superimposed. The tracings with the antagonists present were recorded once the appropriate receptor blockade was established (see Figs. 2, 3). observations on the relative effects of CNQX and AP7 on the local field and cord dorsum potentials add an additional element of specificity to this arrangement. The infusion of CNQX resulted in a very profound reduction of all inputs evoked by stimulation of the skin, and moreover was also associated with a nearly complete blockade of the local and cord dorsum field potentials evoked by electrical stimulation of dorsal rootlets. AP7 resulted in a less substantial reduction of the responses to various cutaneous stimuli, and more importantly also resulted in a less substantial reduction of the cord dorsum and local field potentials. In each of those cases where both CNQX and AP7 showed an effect on a particular response, CNQX was always more effective than AP7 in attenuating the responses of STT neurons. Since the cord potentials are due to the activation of populations of dorsal horn neurons (Beall et al., 1977), this observation suggests that fewer cells of all types are activated in the dorsal horn while CNQX is present than are activated while AP7 is present. This would be consistent with the conclusion of several groups working on either cat or rat spinal cord neurons that non-NMDA receptors mediate monosynaptic actions of primary afferent fibers onto dorsal neurons while NMDA receptors mediate polysynaptic inputs to the dorsal horn (Davies and Watkins, 1983; Peet et al., 1983; Salt and Hill, 1983b; Schouenborg and Sjolund, 1986; Flatman et al., 1987; Childs et al., 1988; Davies, 1988; King et al., 1988; Evans and Long, 1989; Morris, 1989; Dickenson and Sullivan, 1990). This in turn would suggest that activation of STT cells by innocuous stimuli is largely due to monosynaptic connections of large myelinated fibers with STT neurons and that noxious inputs are mediated through both monosynaptic and polysynaptic connections of nociceptors to STT neurons.

We previously reported that iontophoretic release of AP7 had no effect on the mean responses of STT neurons to mechanical stimuli, although some individual cells did show reductions. The effects of AP7 are now more evident, since the administration of the antagonist by microdialysis ensured our saturating a much larger area of each cell's dendritic tree with antagonist than is possible using iontophoretic administration. Similarly, the results with CNQX following microdialysis infusion clearly resulted in a reduction of responses of STT cells to all of the sensory stimuli tested. These results combined suggest that both EAA receptor subtypes are present on STT neurons. Dorsal root axons and dorsal root ganglion cell bodies of all sizes contain both ASP and GLUT (Battaglia et al., 1987; Battaglia and Rustioni, 1988; Westlund et al., 1989, 1990b), and GLUT is found in EAA-containing axon terminals in synaptic contact with STT neurons (Westlund et al., 1990a). STT cells receive synaptic contacts from large myelinated fibers (Foreman et al., 1975), and it would not be unreasonable to expect that some of these fibers also contain EAAs. STT cells also have synaptic contacts from fibers that contain calcitonin gene-related peptide (CGRP) and substance P (SP; Carlton et al., 1985, 1990). Since CGRP in the dorsal horn is contained solely in the terminals of primary afferent fibers and has been colocalized with SP (Chung et al., 1988; Wiesenfeld-Hallin et al., 1989), and SP in turn has been colocalized with EAAs (DeBiasi and Rustioni, 1983), it seems probable that at least some unmyelinated fibers containing EAAs make synaptic contacts on STT neurons. Assuming that GLUT acts as a non-NMDA-preferring ligand and that ASP acts as a NMDA-preferring ligand, as has been suggested previously ( $\mathrm{Da}$ vies and Watkins, 1983; Jahr and Jessell, 1985; Monaghan et al., 1989), it would seem safe to conclude that STT cells have both NMDA and non-NMDA receptors. This is further supported by the observation that isolated dorsal horn neurons, 


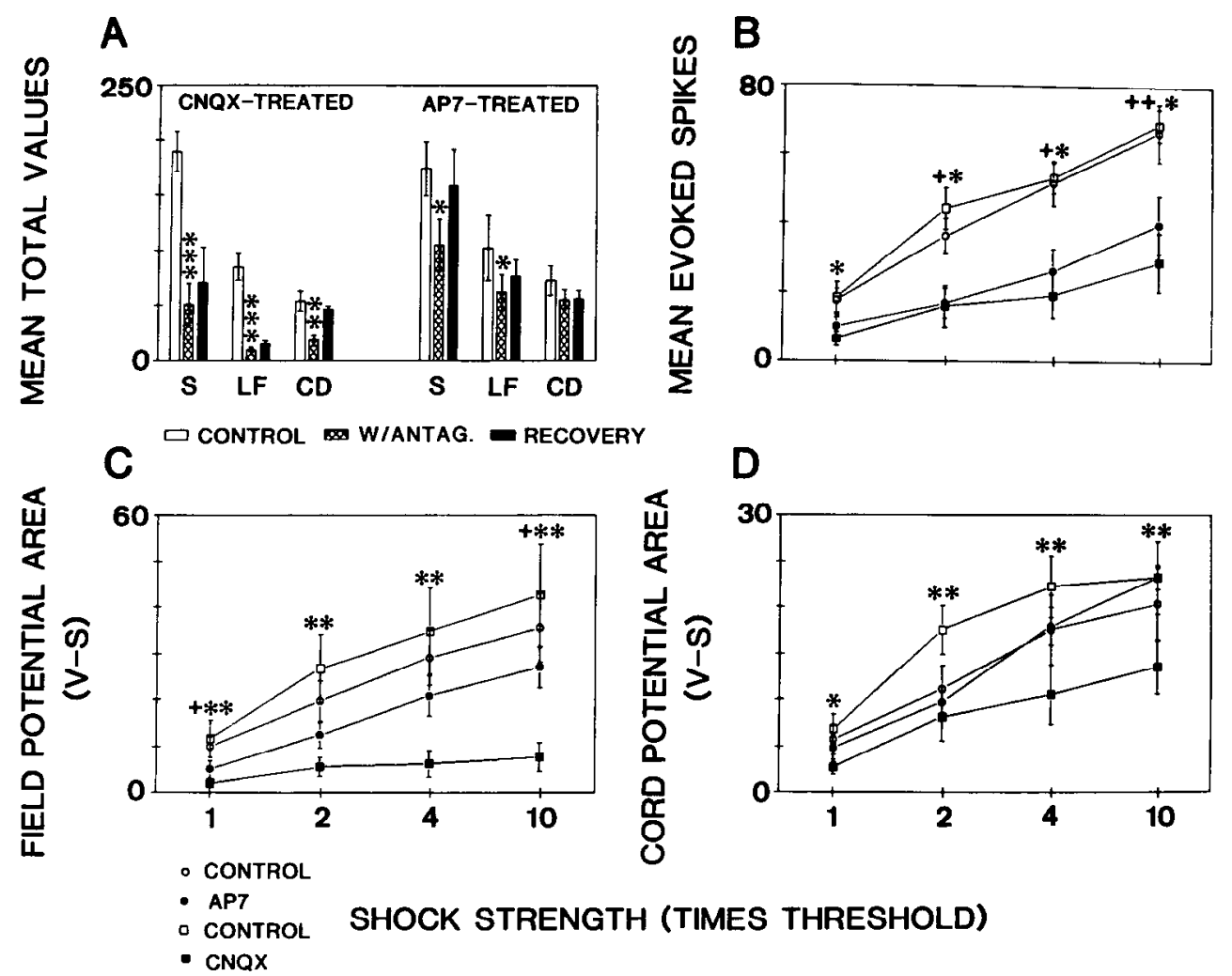

Figure 14. Bar graph and dose-response curves show the group mean values obtained for all cells following graded electrical stimulation of dorsal rootlets. The bar graph shows the mean (and SE) for the total number of spikes evoked in the STT neurons $(S$ ) and the sizes (unit area) of the local field $(L F)$ and cord dorsum $(C D)$ potentials for all four stimulus strengths combined. The control values are shown by the open bars; the values when receptor blockade was established, by the crosshatched bars; and those following washout of the antagonist, by the solid bars. The data for the CNQX-treated cells are at the left, and those for the AP7-treated cells at the right. The line graphs show the mean (and SE) for the number of spikes $(B)$, the sizes (areas) of the local ficld $(C)$, and the cord dorsum potentials $(D)$ before (open symbols) and after establishment of receptor blockade (solid symbols) at each stimulus strength. The circles are for data from the AP7-treated cells, and squares, for data from CNQX-treated cells. The asterisks $\left(^{*}\right)$ in $A$ show the points of statistical differences between the control responses and those obtained in the presence of the antagonists. In $B-D$, however, the asterisks (") show the points of statistical differences between the control responses and only those obtained in the presence of CNQX. The points of statistical difference between the control responses and those obtained with AP7 present for $B-D$ are shown by the pluses $(+){ }^{*}(+), p<0.05 ;^{* *}(++), p<0.01 ;{ }^{* * *}, p<0.001$.

including STT cells, show depolarizations following application of both NMDA and non-NMDA ligands (Chen and Huang, 1991).

In this and in previous studies in this laboratory, we have reported that primate STT cells typically have a substantial level of background activity (Surmeier et al., 1989; Zhang et al., 1991a). The present work has shown that infusion of CNQX reduces the mean background discharge rate of STT cells. Infusion of AP7 also marginally reduced the mean background rate. In six cases (five with AP7, one with CNQX), an increase in background discharge rate was observed following infusion of the antagonists by microdialysis. Occasional increases in background activity of STT cells were also observed following iontophoretic release of AP7 (Dougherty and Willis, 1991a). These observations suggest that there is a tonic activation of NMDA and non-NMDA receptors on STT neurons, as well as on both excitatory and inhibitory interneurons that synapse on STT cells, to determine the background discharge rate. In support of this conclusion is the observation that substantial levels of GLUT and especially ASP are detectable in the extracellular fluid of monkey (Sorkin et al., 1992) and rat spinal cords (Skilling et al., 1988) in the absence of peripheral stimulation. In addition, assuming that the characteristics of NMDA receptors described in vitro (Monaghan et al., 1989) are operational in vivo, STT neurons would need to be tonically depolarized for NMDA receptors to be affected by iontophoretically released agonists. Finally, there is evidence that activation of descending control systems can cause disfacilitation of some STT neurons (Zhang et al., 1990b); disfacilitation depends on the presence of substantial spontaneous activity.

An additional finding of the present study was that infusion of either CNQX or AP7 prevented the sensitization of the responses of STT neurons following intradermal injection of CAP. Sensitization of dorsal horn neurons may underlie the development of secondary hyperalgesia, a "use-dependent" phenomenon in that it is necessary for afferent discharges to arrive at the spinal cord in order for hyperalgesia to develop (Hardy et al., 1952). Assuming that non-NMDA receptors mediate monosynaptic transmission from primary afferent fibers to dorsal horn neurons, it is not surprising that a blockade of this receptor type would prevent sensitization. Infusion of CNQX would essentially have resulted in anesthesia by blocking the responses of most dorsal horn neurons and thus would prevent any secondary responses from occurring. Wc also found that blockade of NMDA receptors prevents sensitization without affecting responsiveness of STT cells to BRUSH or PRESS stimuli. This 


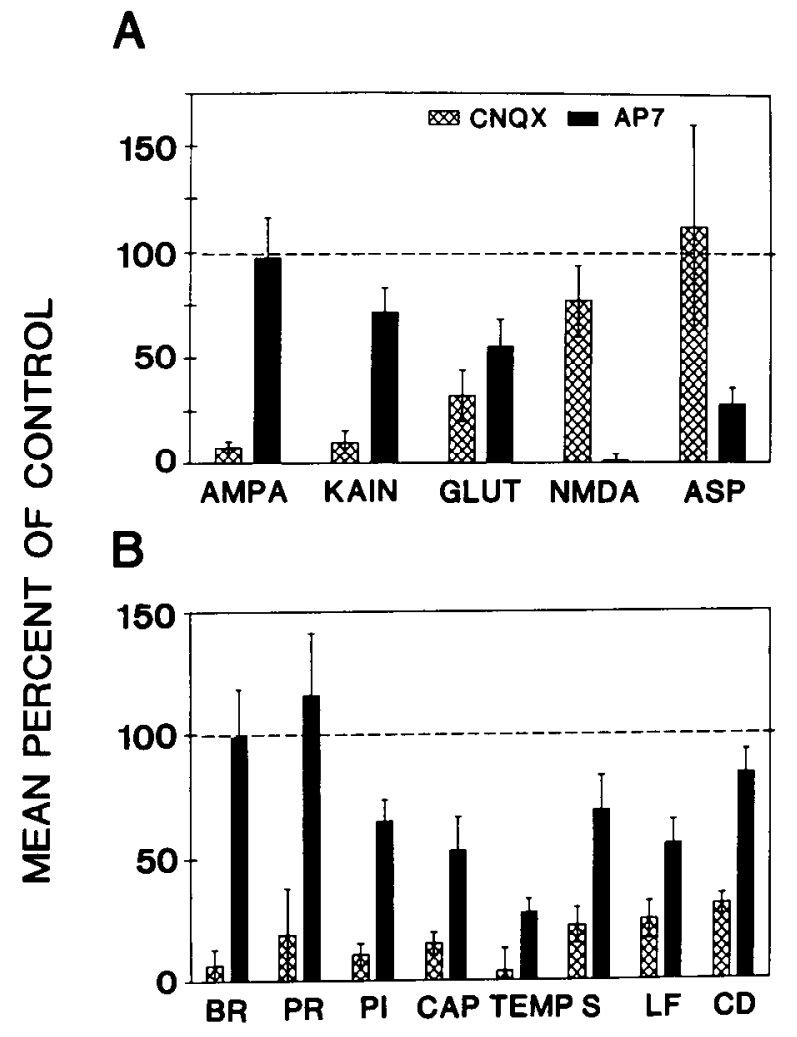

Figure 15. Bar graphs show the mean (and SE) percentage of the control response to each EAA $(A)$ or test stimulus $(B)$ during infusion of CNQX (crosshatched bars) or AP7 (solid bars). The control response equals $100 \%$ (broken line). Abbreviations are as in previous figures.

suggests that NMDA receptors are not an essential site for the initial transmission of sensory information from undamaged skin but play a key role in the development of secondary hyperalgesia following an injury to skin (cf. Headley et al., 1987, 1989). Assuming that NMDA receptors mediate polysynaptic actions on STT cells, this suggests that the hyperalgesia produced by CAP is largely due to an enhancement of activity arriving at STT neurons from interneurons of the spinal cord. This conclusion in turn suggests that, on those occasions when we did find that AP7 caused a decrease in background activity and of the responses of STT cells to innocuous stimuli, it is possible these cells (or adjacent interneurons) were previously sensitized by the surgical preparation. Each of these conclusions concerning the role of NMDA receptors in the dorsal horn are in agreement with proposals by others that NMDA receptors participate in the "windup" of dorsal horn neurons and in the enhancement of flexion reflexes following high-intensity electrical stimulation of afferent fibers or peripheral tissue injury or inflammation (Woolf, 1983; Davies and Lodge, 1987; Schouenborg and Dickenson, 1988; Hoheisel and Mense, 1989; Woolf and Thompson, 1991; Schaible, 1992).

In conclusion, the present study has shown that EAAs acting on both NMDA and non-NMDA receptors activate STT neurons in response to diverse types of cutaneous stimuli. Our results are consistent with the idea that non-NMDA receptors mediate the responses at the initial synapse within the dorsal horn between primary afferents and dorsal horn neurons, while NMDA receptors are involved in polysynaptic events. Furthermore, non-NMDA receptors appear to be in the initial stage of the pathway for the chemical transmission of sensory infor- mation from primary afferent fibers to dorsal horn neurons while NMDA receptors appear to be centrally involved in the production of enhanced responsiveness of dorsal horn neurons following tissue-damaging stimuli. Since the transmission of sensory information by monkey STT cells closely parallels the psychophysical responses of humans to cutaneous stimuli (LaMotte et al., 1991), these findings suggest that under circumstances where the responses of dorsal horn neurons to nonNMDA ligands are enhanced, the perceived result by humans would be allodynia as well as hyperalgesia, while enhancement of the responses of cells to NMDA ligands would produce hyperalgesia alone. Recent findings suggest that one way in which such states could be produced is by corelease of neuropeptides, such as SP, and EAAs from primary afferent fibers in to the dorsal horn (Randic et al., 1990; Dougherty and Willis, 1991b). Finally, the background activity of STT neurons appears to be due at least in part to a tonic release of EAAs acting particularly at the non-NMDA receptor subtype, but in some circumstances at NMDA receptors as well.

\section{References}

Aanonsen LM, Wilcox GL (1987) Nociceptive action of excitatory amino acids in the mouse: effects of spinally administered opioids, phencyclidine and sigma agonists. J Pharmacol Exp Ther 243:9-19.

Aanonsen LM, Lei S, Wilcox GL (1990) Excitatory amino acid receptors and nociccptive ncurotransmission in rat spinal cord. Pain 41:309-321.

Battaglia G, Rustioni A (1988) Coexistence of glutamate and substance $P$ in dorsal root ganglion neurons of the rat and monkey. $J$ Comp Neurol 277:302-312.

Battaglia G, Rustioni A, Altshuler RA, Petrusz P (1987) Glutamic acid coexists with substance $P$ in some primary sensory neurons. In: Fine afferent nerve fibers and pain (Schmidt RF, Schaible H-G, VahleHinz C, eds), pp. 77-84. Weinheim: VCH.

Baumann TK, Simone DA, Shain CN, LaMotte RH (1991) Neurogenic hyperalgesia: the search for the primary cutaneous afferent fibers that contribute to capsaicin-induced pain and hyperalgesia. J Neurophysiol $66: 212-227$.

Beall JE, Applebaum AE, Foreman RD, Willis WD (1977) Spinal cord potentials evoked by cutaneous afferents in the monkcy. J Ncurophysiol 40:199-211.

Benveniste H, Hansen AJ, Ottosen NS (1990) Determination of brain interstitial concentrations by microdialysis. J Neurochem 52:17411750.

Cahusac PMB, Evans RH, Hill RG, Rodriquez RE, Smith DAS (1984) The behavioural effects of an $N$-methylaspartate receptor antagonist following application to the lumbar spinal cord of conscious rats. Neuropharmacology 23:719-724.

Carlton SM, LaMotte CC, Honda CN, Surmeier DJ, DeLanerolle NC, Willis WD (1985) Ultrastructural analysis of substance $P$ and other synaptic profiles innervating an identified primate spinothalamic tract neuron. Soc Neurosci Abstr 11:578.

Carlton SM, Westlund KN, Zhang D, Sorkin LS, Willis WD (1990) Calcitonin gene-related peptide containing primary afferent fibers synapse on primate spinothalamic tract cells. Neurosci Lett 109:76-81.

Chen L, Huang L-YM (1991) Sustained potentiation of NMDA receptor-mediated glutamate responses through activation of protein kinase $C$ by a $\mu$ opioid. Neuron 7:319-326.

Childs AM, Evans RH, Watkins JC (1988) The pharmacological selectivity of three NMDA antagonists. Eur J Pharmacol 145:81-86.

Chung K, Lee WT, Carlton SM (1988) The effects of dorsal rhizotomy and spinal cord isolation on calcitonin gene-related peptide-labeled terminals in the rat lumbar dorsal horn. Neurosci Lett 90:27-32.

Cotman CW, Monaghan DT, Ottersen OP, Storm-Mathisen J (1987) Anatomical organization of excitatory amino acid receptors and their pathways. Trends Neurosci 10:273-280.

Davies J (1988) A reappraisal of the role of NMDA and non-NMDA receptors in neurotransmission in the cat dorsal horn. In: Frontiers in excitatory amino acid research (Cavalhiero EA, Lehman J, Turski L, eds), pp. 355-362. New York: Liss. 
Davies J, Watkins JC (1983) Role of excitatory amino acid receptors in mono- and polysynaptic excitation in the cat spinal cord. Exp Brain Res 49:280-290.

Davies SN, Lodge D (1987) Evidence for involvement of $N$-methylaspartate receptors in "wind-up" of class 2 neurons in the dorsal horn of the rat. Brain Res 424:402-406.

DeBiasi S, Rustioni A (1983) Glutamate and substance P coexist in primary afferent terminals in superficial laminae of spinal cord. Proc Natl Acad Sci USA 85:7820-7824

Dickenson AH, Sullivan AF (1990) Differential effects of excitatory amino acid antagonists on dorsal horn nociceptive neurones in the rat. Brain Res 506:31-39.

Dougherty PM, Willis WD (1991a) Modification of the responses of spinothalamic tract neurons to mechanical stimulation by excitatory amino acids and an antagonist. Brain Res 542:15-22.

Dougherty PM, Willis WD (1991b) Enhancement of spinothalamic neuron responses to chemical and mechanical stimuli following combined microiontophoretic application of $N$-methyl-D-aspartic acid and substance P. Pain 47:85-93

Dougherty PM, Willis WD (1992) Enhanced responses of spinothalamic tract neurons to excitatory amino acids accompany the generation of capsaicin-induced hyperalgesia in the monkey. J Neurosci 12:883-894

Dougherty PM, Sluka KA, Sorkin LS, Westlund KN, Willis WD (1992) Enhanced responses of spinothalamic tract neurons to excitatory amino acids parallel the gencration of acute arthritis in the monkey. Brain Res Rev, 17:1-14.

Evans RH, Long SK (1989) Primary afferent depolarization in the rat spinal cord is mediated by pathways utilising NMDA and non-NMDA receptors. Neurosci Lett 100:231-236.

Fagg GE, Foster AC (1983) Amino acid neurotransmitters and their pathways in the mammalian central nervous system. Neuroscience 9:701-719.

Flatman JA, Durand J, Engberg I, Lambert DC (1987) Blocking the monosynaptic EPSP in spinal cord motoneurones with inhibitors of amino-acid excitation. In: Excitatory amino acid transmission (Hicks TP, Lodge D, McLennan H, eds), pp 285-292. New York: Liss.

Foreman RD, Applebaum AE, Beall JE, Trevino DL, Willis WD (1975) Responses of primate spinothalamic tract neurons to electrical stimulation of hindlimb peripheral nerves. J Neurophysiol 38:132-145.

Gerber G, Randic M (1989a) Excitatory amino acid-mediated components of synaptically evoked input from dorsal roots to deep dorsal horn neurons in the rat spinal cord slice. Neurosci Lett 106:211-219.

Gerber G, Randic M (1989b) Participation of excitatory amino acid receptors in the slow excitatory synaptic transmission in the rat spinal dorsal horn in vitro. Neurosci Lett 106:220-228.

Hardy JD, Wolff HG, Goodell H (1952) Pain sensations and reactions. New York: Williams and Wilkins. Reprint. New York: Hafner, 1967.

Headley PM, Parsons CG, West DC (1987) The role of $N$-methylaspartate receptors in mediating responses of rat and cat spinal neurones to defined sensory stimuli. J Physiol (Lond) 385:169-188.

Headley PM, Parsons CG, West DC, Dong X-W (1989) On the influence of anesthesia, stimulus intensity and drug access in pharmacological tests of sensory processing in the superficial dorsal horn. In: Processing of sensory information in the superficial dorsal horn of the spinal cord (Cervero F, Bennett GJ, Headley PM, eds), pp 499511. New York: Plenum.

Hoheisel U, Mense S (1989) Long-term changes in discharge behavior of cat dorsal horn neurones following noxious stimulation of deep tissues. Pain 36:239-247.

Jahr CE, Jessell TM (1985) Synaptic transmission between dorsal root ganglion and dorsal horn neurons in culture: antagonism of monosynaptic excitatory postsynaptic potentials and glutamate excitation by kynurenate. J Neurosci 5:2281-2289.

Kangrga I, Randic M (1991) Outflow of endogenous aspartate and glutamate from the rat spinal dorsal horn in vitro by activation of low- and high-threshold primary afferent fibers. Modulation by $\mu$-opioids. Brain Res 553:347-352.

King AE, Thompson SWN, Urban L, WoolfCJ (1988) An intracellular analysis of amino acid induced excitations of deep dorsal horn neurones in the rat spinal cord slice. Neurosci Lett 89:286-292.

LaMotte RH, Shain CN, Simone DA, Tsai E-FP (1991) Neurogenic hyperalgesia: psychophysical studies of underlying mechanisms. J Neurophysiol 66:190-211.

Liu D, Sorkin LS, Hughes MG, McAdoo DJ (1989) Release of as- partate and glutamate in the dorsal horn of the cat lumbar spinal cord in response to intradermal capsaicin injection. Soc Neurosci Abstr 15:549.

Mayer ML, Westbrook GL (1987) The physiology of excitatory amino acids in the vertebrate central nervous system. Prog Neurobiol 28 : 197-276.

McLennan H, Lodge D (1979) The antagonism of amino acid-induced excitation of spinal neurones in the cat. Brain Res 169:83-90.

Monaghan DT, Bridges RJ, Cotman CW (1989) The excitatory amino acid receptors: their classes, pharmacology, and distinct properties in the function of the central nervous system. Annu Rev Pharmacol Toxicol 29:365-402.

Morris R (1989) Responses of spinal dorsal horn neurones evoked by myelinated primary afferent stimulation are blocked by excitatory amino acid antagonists acting at kainate/quisqualate receptors. Neurosci Lett 105:79-85.

Owens CM (1991) Plastic changes in the responses of primate spinothalamic neurons, pp 86-89. PhD thesis, University of Texas Medical Branch.

Peet MJ, Leah JD, Curtis DR (1983) Antagonists of synaptic and amino acid excitation of neurones in the cat spinal cord. Brain Res 266:83-95.

Perl ER (1968) Myelinated afferent fibres innervating the primate skin and their response to noxious stimuli. J Physiol (Lond) 197:593-615.

Puil E (1981) $S$-glutamate: its interactions with spinal neurons. Brain Res Rev 3:229-322.

Raigorodsky G, Urca G (1987) Intrathecal $N$-methyl-D-aspartate (NMDA) activates both nociceptive and antinociceptive systems. Brain Res 422:1 58-162.

Rainnie DG, Asprodini EK, Shinnick-Gallagher P (1991) Excitatory transmission in the basolateral amygdala. Neuroscience 66:989-998.

Randic M, Hecimovic H, Ryu PD (1990) Substance P modulates glutamate-induced currents in acutely isolated rat dorsal horn neurones. Neurosci Lett 117:74-80.

Rizzoli AA (1968) Distribution of glutamic acid, aspartic acid, $\gamma$-aminobutyric acid and glycine in six areas of cat spinal cord before and after transection. Brain Res 11:11-18.

Rustioni A, Weinberg RJ (1989) Somatosensory system. In: Handbook of chemical neuroanatomy, Vol 5, Integrated systems of the CNS, Pt II (Bjorklund A, Hokfelt T, Swanson LW, eds), pp x-xx.

Salt TE, Hill RG (1983a) Neurotransmitter candidates of somatosensory primary afferent fibres. Neuroscience 10:1083-1103.

Salt TE, Hill RG (1983b) Pharmacological differentiation between responses of rat medullary dorsal horn neurons to noxious mechanical and noxious thermal cutaneous stimuli. Brain Res 263:167-171.

Schaible H-G (1992) Nociceptive processes in the spinal cord evoked by acute arthritis. In: The second Bristol-Myers symposium on pain research, hyperalgesia and allodynia (Willis WD, ed), in press. New York: Raven.

Schneider SP, Perl ER (1985) Selective excitation of neurons in the mammalian spinal dorsal horn by aspartate and glutamatc in vitro: correlation with location and excitatory input. Brain Res 360:339343.

Schouenborg J, Dickenson A (1988) Long-lasting neuronal activity in rat dorsal horn evoked by impulses in cutaneous fibres during noxious mechanical stimulation. Brain Res 439:56-63.

Schouenborg J, Sjolund BH (1986) First-order nociceptive synapses in rat dorsal horn are blocked by an amino acid antagonist. Brain Res 376:394-398.

Simone DA, Ngeow JYF, Putterman GJ, LaMotte RH (1987) Hyperalgesia to heat after intradermal injection of capsaicin. Brain Res 418:201-203.

Simone DA, Baumann TK, Collins JG, LaMotte RH (1989) Sensitization of cat dorsal horn neurons to innocuous mechanical stimulation after intradermal injection of capsaicin. Brain Res 486:185189.

Simone DA, Sorkin LS, Oh U, Chung JM, Owens C, LaMotte RH, Willis WD (1991) Neurogenic hyperalgesia: central neural correlates in responses of spinothalamic tract neurons. J Neurophysiol 66:228246.

Skilling SR, Smullin DH, Beitz AJ, Larson AA (1988) Extracellular amino acid concentrations in the dorsal spinal cord of freely moving rats following veratridine and nociceptive stimulation. J Neurochem $51: 127-132$

Sorkin LS, Steinman JL, Hughes MG, Willis WD, McAdoo DJ (1988) 
Microdialysis recovery of serotonin released in spinal cord dorsal horn. J Neurosci Methods 23:131-138.

Sorkin LS, Westlund KN, Sluka KA, Dougherty PM, Willis WD (1992) Neural changes in acute arthritis in monkeys. IV. Time course of amino acid release into the lumbar dorsal horn. Brain Res Rev 17: $39-50$.

Storm-Mathisen J, Ottersen OP (1987) Tracing of neurons with glutamate or $\gamma$-aminobutyrate as putative transmitters. Biochem Soc Trans 15:210-213.

Surmeier DJ, Honda CN, Willis WD (1989) Patterns of spontaneous discharge in primate spinothalamic neurons. J Neurophysiol 61:106115.

Wanaka A, Shiotani Y, Kiyama H, Matsuyama T, Kamada T, Shiosaka S, Tohyama M (1987) Glutamate-like immunoreactive structures in primary sensory neurons in the rat detected by a specific antiserum against glutamate. Exp Brain Res 65:691-694.

Watkins JC, Evans RH (1981) Excitatory amino acid transmitters. Annu Rev Pharmacol Toxicol 21:165-204.

Watkins JC, Olverman HJ (1987) Agonists and antagonists for excitatory amino acid receptors. Trends Neurosci 10:265-272.

Westlund KN, McNeill DL, Patterson JT, Coggeshall RE (1989) Aspartate immunoreactive axons in normal rat L4 dorsal roots. Brain Res 489:347-351.

Westlund KN, Carlton SM, Zhang D, Willis WD (1990a) Direct glutamergic innervation of primate spinothalamic tract neurons. Soc Neurosci Abstr 16:704.

Westlund KN, McNeill DL, Coggeshall RE (1990b) Glutamate immunoreactivity in rat dorsal root axons. Neurosci Lett 96:13-17.

Wiesenfeld-Hallin Z, Hokfelt T, Lundberg JM, Forssman WG, Reinecke M, Tchopp FA, Fischer JA (1989) Immunoreactive calcitonin generelated peptide and substance $P$ coexist in sensory neurons to the spinal cord and interact in spinal behavioral responses of the rat. Neurosci Lett 52:199-204.

Wilcox GL (1991) Excitatory neurotransmitters and pain. In: Pro- ceedings of the VIth World Congress on Pain (Bond MR, Charlton JE, Woolf CJ, eds), pp 97-117. Amsterdam: Elsevier.

Wilcox GL, Giesler GJ (1984) An instrument using a multiple layer peltier device to change skin temperature rapidly. Brain Res Bull 12: 143-146.

Willcockson WS, Chung JM, Hori Y, Lee KH, Willis WD (1984a) Effects of iontophoretically released amino acids and amines on primate spinothalamic tract cells. J Neurosci 4:732-740.

Willcockson WS, Chung JM, Hori Y, Lee KH, Willis WD (1984b) Effect of iontophoretically released peptides on primate spinothalamic tract cells. J Neurosci 4:741-750.

Willis WD, Maunz RA, Foreman RD, Coulter JD (1975) Static and dynamic response of spinothalamic tract neurons to mechanical stimuli. J Neurophysiol 38:587-600.

Woolf CJ (1983) Evidence for a central component of post-injury pain hypersensitivity. Nature 306:686-688.

Woolf CJ, Thompson SWN (1991) The induction and maintenance of central sensitization is dependent on $N$-methyl-D-aspartic acid receptor activation; implications for the treatment of post-injury pain hypersensitivity states. Pain 44:293-299.

Yaksh TL (1989) Behavioral and autonomic correlates of the tactile evoked allodynia produced by spinal glycine inhibition: effects of modulatory receptor systems and excitatory amino acid antagonists. Pain 37:111-123.

Zhang D, Owens CM, Willis WD (1991a) Intracellular study of electrophysiological features of primate spinothalamic tract neurons and their responses to afferent inputs. J Neurophysiol 65:1554-1566.

Zhang D, Owens CM, Willis WD (1991b) Two forms of inhibition of spinothalamic tract neurons produced by stimulation of the periaqueductal gray and the cerebral cortex. J Neurophysiol 65:1567-1579.

Zieglgansberger $W$, Herz A (1971) Changes of cutaneous receptive fields of spino-cervical tract neurones and other dorsal horn neurones by microelectrophoretically administered amino acids. Exp Brain Res 13:111-126. 